Paper accepted for publication in The Journal of the Acoustical Society of America 23 June 2020

\title{
Modelling wheel/rail rolling noise for a high-speed train running along an infinitely long periodic slab track
}

\author{
Xiaozhen Sheng ${ }^{1 *}$, Gong Cheng ${ }^{2}$, David Thompson ${ }^{3}$ \\ ${ }^{1}$ School of Urban Railway Transportation, Shanghai University of Engineering Science, Shanghai, 201620, \\ China \\ ${ }^{2}$ State Key Laboratory of Traction Power, Southwest Jiaotong University, Chengdu, 610031, China \\ ${ }^{3}$ Institute of Sound and Vibration Research, University of Southampton, Southampton, SO17 1BJ, UK \\ *Correspondence author. Email: shengxiaozhen@ hotmail.com
}

\section{ABSTRACT}

Around 35,000 km high-speed railways are in operation in China with a maximum speed of 350 $\mathrm{km} / \mathrm{h}$. The main track form on the high-speed lines is non-ballasted slab track. Measurements show that, at high speeds, rolling noise is still the dominant source for both interior and exterior noise. Although rolling noise modelling has been investigated for more than 30 years, a train running at 350 $\mathrm{km} / \mathrm{h}$ or higher along a non-ballasted slab track introduces a number of new factors which have not been adequately addressed in the past. The aim of this paper is to describe an approach that brings together elements that have been developed recently to model rolling noise for a high-speed train running on a slab track. Features of the approach include modelling interactions between multiple moving and rotating wheelsets with an infinitely long periodic track, treating all the radiators as moving sources, and directly predicting sound pressure frequency spectra for observation points near the track. Results are produced for a typical Chinese high-speed train and track, including wheel and rail receptances, wheel/rail forces, comparison of rolling noise with measured pass-by noise, dependence on train speed, and contributions from the wheelset, rail and slab.

\section{KEY WORDS}

Rolling noise; railway noise; high-speed train; slab track.

\section{INTRODUCTION}

China has seen a boom in high-speed railway network since the first line was first opened in 2008. After only 12 years, around 35,000 km of high-speed railways are in operation with a maximum speed of up to $350 \mathrm{~km} / \mathrm{h}$. Trains with even higher speeds are also under development. The main track form on the high-speed lines is the non-ballasted slab track.

Such a rapid development greatly benefits the country and its people, but at the same time highspeed lines also significantly impact the environment by generating noise. To control the impact, a 
detailed understanding of the noise sources must be achieved. Therefore, a large number of in-situ noise measurements have been performed. Measured data suggest that at high speeds, noise from the bogie area is the dominant noise source for both interior and exterior noise [1]. The importance of bogies for external noise is also noted in Ref. [2] for Korean high-speed trains.

At high speeds, noise from the bogie region mainly consists of two parts. One is rolling noise generated from wheel/rail interaction and the resulting vibration, and the other is generated from aerodynamic interactions between the bogie and air. It is understood that the former is dominant over the latter from around $50 \mathrm{~km} / \mathrm{h}$ up to $300 \mathrm{~km} / \mathrm{h}$ [3], whereas aerodynamic noise increases with speed at a higher rate and may become dominant at a sufficiently high speed [4]. However, for a high-speed train running along a non-ballasted slab track, the relative importance of the various sources, particularly at speeds of $350 \mathrm{~km} / \mathrm{h}$ and above, and how they depend on train speed and other design and operational parameters, are still questions to be answered.

It is difficult to answer these questions solely by measurement, since measured noise is a mixture of (mainly) rolling noise and aerodynamic noise. An alternative approach is to develop theoretical models which can be used to predict each of the noise sources. This paper focuses on developing a model for rolling noise for high-speed trains.

Research into rolling noise modelling has been performed for more than 30 years, mainly for ballasted tracks. Due to the fact that the frequency range extends up to several thousand hertz and a mildly stochastic wheel-rail roughness can be normally assumed (this is especially true for high-speed railways), most models are linear and use a frequency domain approach [5]. The first models were developed by Remington using analytical methods [6]. These were extended by Thompson and implemented in the TWINS model which has been validated by extensive field tests [7, 8]. Some comparisons were also made with measurements from high speed trains $[9,10]$. Improvements to the TWINS model have been carried out by Zhang et al. [11-13] who improved the prediction of sound radiation from the track. $\mathrm{Wu}[14,15]$ developed an approach for including parametric excitation. Nordborg [16] also investigated the role in rolling noise generation of parametric excitation, suggesting that parametric excitation can be a major excitation mechanism for a rail on stiff pads.

If non-linearity in the wheel/track system has to be considered, or if the wheel/rail irregularities are discrete, e.g. a wheel flat or a rail joint, wheel/rail noise prediction is normally performed in the time domain [17-19]. Extension of a time domain vehicle-track interaction model is also attempted [20] to predict wheel/rail noise.

Although there are many papers in the literature on different aspects of rolling noise modelling, a train running at $350 \mathrm{~km} / \mathrm{h}$ or higher along a non-ballasted slab track introduces a number of new 
factors which have not been adequately addressed in the past. These include, for example, wheel rotation, sound reflection from the slab, and the fast movement of the sources as observed from a receiver fixed relative to the ground. Regarding wheel rotation, Thompson [21] replaced the rotation of the wheel with a rotating load. Since the wheel is not in rotation, the structural effect of rotation, such as centrifugal stiffening or softening and Coriolis forces, are all excluded. Although a complete formulation is given in Refs [22, 23] for the structural vibration of a rotating wheelset, the effect of wheel rotation on rolling noise has not been investigated.

The aim of this paper is to describe an integrated approach that brings together elements that have been developed in the past few years to model rolling noise from a high-speed train running on a slab track. This is presented in Section II. In Section III results are presented for a typical Chinese highspeed train and track, including wheel and rail receptances, wheel/rail forces, rolling noise compared with measured pass-by noise, dependence on train speed and contributions from the wheelset, rail and slab. The paper is concluded in Section IV.

Although the wheelsets are allowed in the model to rotate and move along the track, the approach is nevertheless essentially a frequency domain approach, which could also allow for frequencydependent track parameters. For high-speed railway operations, the track and trains must be maintained to the highest standard, and wheel/rail roughness is low compared with other types of railway. This means that the wheel/rail contact spring can be linearized. On the other hand, high train speeds and relatively soft rail pads make the sleeper-passing frequency (for slab tracks, this refers to the passing frequency of the discrete rail fastener systems) much closer to the rail-on-railpad resonance frequency, increasing the importance of the moving axle loads and interactions between multiple wheelsets. The approach takes these effects, among others, into account naturally.

\section{THE MODELLING APPROACH}

As a train wheelset rotates and moves along the track, vertical relative displacements between the wheels and rails are generated by the roughness (or unevenness) on the wheel/rail rolling surfaces. In addition, parametric excitation is induced by the moving axle load and periodic variations in track stiffness. These two mechanisms induce dynamic forces that excite the wheelset and the track, causing them to vibrate in a complex manner. Sound radiated by such vibration is collectively called rolling noise.

The roughness of the right wheel/rail is denoted by $z_{\mathrm{R}}(x)$, and that of the left wheel/rail is denoted by $z_{\mathrm{L}}(x)$, where $x$ is the longitudinal coordinate. Due to the symmetry of the wheel/rail system about the track centreline, the rolling noise generated by the roughness and the moving axle load can be decomposed into two parts, one being due to a symmetric roughness excitation and the moving axle 
load, and the other due to an antisymmetric roughness excitation. The symmetric roughness is given by $0.5\left[z_{\mathrm{R}}(x)+z_{\mathrm{L}}(x)\right]$, and the antisymmetric roughness is given by $0.5\left[z_{\mathrm{R}}(x)-z_{\mathrm{L}}(x)\right]$. For rolling noise prediction, the right and left wheel/rail roughness can be regarded as incoherent [24]. Ref. [24] shows that the two rails can be considered as uncorrelated for wavelengths shorter than about $3 \mathrm{~m}$. Hence, rolling noise generated by the symmetric roughness and that by the antisymmetric one should be added incoherently to give the total rolling noise.

The modelling approach is presented mainly for the symmetric roughness, but it is equally applicable to the antisymmetric roughness. Based on the methodologies adopted, the prediction of rolling noise can be divided into the following six steps:

(1) Prediction of wheelset dynamics, i.e., to calculate the vibration of a rotating wheelset due to unit harmonic forces at the wheel/rail contact points for a range of frequencies;

(2) Prediction of track dynamics, i.e., to calculate the vibration of the track as an infinitely long periodic structure subject to a unit vertical harmonic force moving along each rail for a range of frequencies;

(3) Prediction of wheel/rail interaction, i.e., to calculate dynamic wheel/rail forces generated by wheel/rail roughness as wheelsets rotate and move along the track;

(4) Prediction of wheel radiation, i.e., to calculate the sound pressure spectrum generated by the vibration of the wheelset predicted in Step (1);

(5) Prediction of track radiation, i.e., to calculate the sound pressure spectrum generated by the track due to a travelling harmonic vibrational wave for a range of frequencies and wavenumbers;

(6) Prediction of wheel/rail rolling noise, i.e., to calculate sound pressure spectra radiated from the wheelsets and track, due to the wheel/rail roughness, at a receiver next to the track that is fixed relative to the ground.

These steps are explained in more detail in the following sub-sections.

\section{A. Prediction of wheelset dynamics}

In this step, the vibration of a rotating wheelset due to a unit harmonic force applied at a wheel/rail contact point is calculated. The calculation methodology is briefly described here. More details can be found in Ref. [25] (NB: only a wheel, of which the axis is assumed to vibrate vertically only, is dealt with in Ref. [25]. An extension to Ref. [25] has been performed to deal with a rotating wheelset. This extension allows the wheelset to have five rigid body motions, as descried below.) 


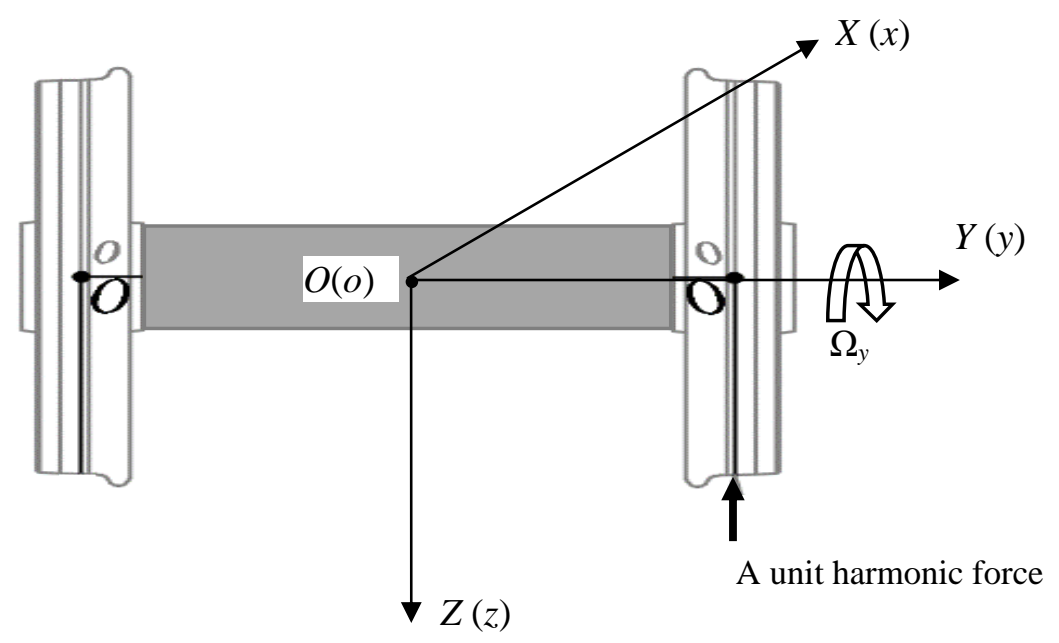

Fig. 1. Coordinate systems used for, and the initial position of, the wheelset.

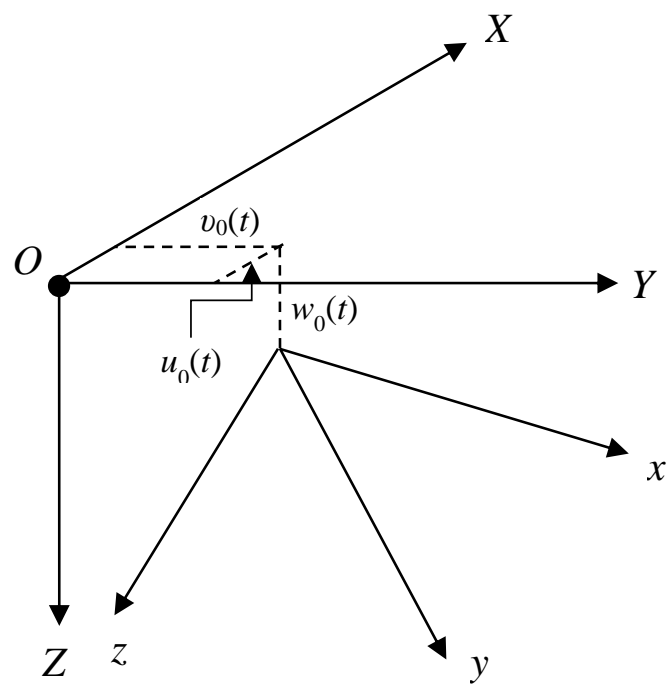

(a)

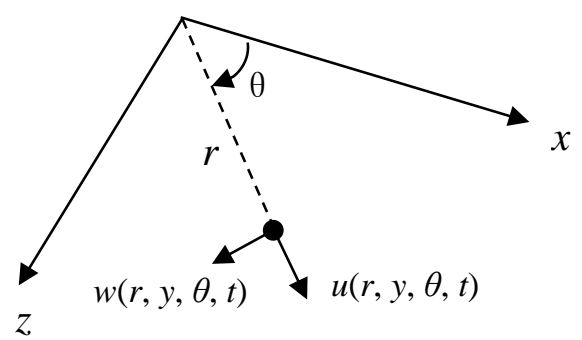

(b)

Fig. 2. Rigid-body motions and elastic displacements. (a) Rigid-body motion components; (b) elastic displacement components.

As shown in Fig. 1, OXYZ is an inertial coordinate system, which moves uniformly in the track direction at the train speed. The coordinate system oxyz is rigidly attached to the wheelset with the $y$ axis coinciding with the wheelset axis and the origin being at the mass centre of the wheelset. At $t=$

1340 these two coordinate systems overlap each other. The wheelset rotates uniformly about the $y$-axis at $\Omega_{y}$ (in rad/s) in the direction shown. The bold arrow in Fig.1 represents an external force applied to the wheelset. Subject to this force, the wheelset deforms and vibrates, in addition to the preassumed rotation. The position at instant $t$ of the deformed wheelset may be achieved by two simultaneous actions, a rigid-body motion and an elastic deformation. 
(1) A translational motion in which the origin $o$ has displacement $u_{0}(t)$ in the $X$-direction, $v_{0}(t)$ in

141 the $Y$-direction and $w_{0}(t)$ in the $Z$-direction;

142 (2) The new coordinate system is rotated by an angle $\alpha(t)$ about the new $X$-axis (this is the roll 143 angle of the wheelset);

(3) It is then rotated by an angle $\beta(t)$ about the new $Z$-axis (this is the yaw angle of the wheelset), achieving the position of the wheelset axis;

(4) Finally the wheelset is rotated by an angle $\Omega_{y} t$ about its axis, and the coordinate system becomes $o x y z$, as shown in Fig. 2(a). Note that the direction of this rotation is opposite to the direction of the $y$-axis.

In Ref. [25] and its extension, a finite element scheme, which only requires a two-dimensional (2D) mesh over the cross-section containing the wheel axis, is combined with the momentum law and the momentum torque law to establish partial differential equations of motion for the wheelset. The elastic displacement is described in terms of cylindrical coordinates $(r, y, \theta)$ (Fig. 2(b)), and is a $2 \pi$ periodic function of the circumferential angle $\theta$. By decomposing the elastic displacement, using Fourier series, into components at particular circumferential orders, the partial differential equations become ordinary differential equations governing these components.

For a harmonic load, such as a harmonic wheel/rail force, that acts at a fixed point in space while the wheelset is rotating past it about its axis, these ordinary differential equations can be solved algebraically. It is found that the displacement of the loading point, which is stationary if observed from the train, is also harmonic at the same frequency as the applied force. Thus the concept of receptance can be readily defined and calculated for the rotating wheelset at a wheel/rail contact point $[21,25]$. Such a receptance may be termed the receptance of the rotating wheelset. This receptance is used for calculating wheel/rail forces. Moreover, the response of each point on the wheelset in the frame of reference fixed with respect to the contact point is also harmonic, although the response in the frame rotating with the wheel is not. This feature is used for the calculation of sound radiated from the wheelset.

Now it is assumed that the wheelset is symmetric about the centre of the axle. If a unit vertical harmonic load is applied at the right wheel/rail contact point, the vertical displacement of the wheelset at this point is denoted by $\alpha_{\mathrm{w} 11}$, and the vertical displacement at the left wheel/rail contact point is denoted by $\alpha_{\mathrm{w} 21}$. The same responses apply on the opposite wheels if the left-hand wheel is excited. If both wheel/rail points are subject to a unit vertical harmonic force symmetrically, the vertical 
displacement at the wheel/rail contact point is given by $\alpha_{\mathrm{w} 11}+\alpha_{\mathrm{w} 21}$. On the other hand, if each wheel/rail point is subject to a unit vertical harmonic force anti-symmetrically, the displacement of the wheel/rail contact point is given by $\alpha_{\mathrm{w} 11}-\alpha_{\mathrm{w} 21}$ for the right one, and $-\left(\alpha_{\mathrm{w} 11}-\alpha_{\mathrm{w} 21}\right)$ for the left one.

\section{B. Prediction of track dynamics}

The track vibration due to a unit vertical harmonic wheel/rail force acting on one rail and moving along the track is briefly described here. It is assumed that the force acts on the right rail which is called the loaded rail and the other rail is called the unloaded rail. More detail is given in Ref. [26] for a conventional ballasted track, Ref. [27] for a track with rail dampers and Ref. [28] for a highspeed slab track as considered in this paper.

\section{Description of the track}

A high-speed slab track consists of two rails, connected by discrete rail fastener systems to finite length pre-stressed concrete slabs with cast-in sleepers, below which is a layer of concrete-asphalt (CA) mortar and a concrete base (Fig. 3). In assessing rolling noise, the concrete base may be approximated to be rigid. The track is assumed to be infinitely long. The length of each slab is denoted by $L$. In its design state, the track structure can be idealised as being a periodic structure with period $L$. Each segment of length $L$ in the $x$-direction is identical to the one found in the interval $[0, L]$, which is termed the 0th bay. The track consists of an infinite number of identical bays of length $L$, and the $j$ th bay, where $j=-\infty, \cdots,-1,0,1,2, \cdots+\infty$, is located between $x=j L$ and $x=(j+1) L$. Within each bay, there are $S$ rail fasteners which connect the rail and a slab. The $s$ th fastener in the 0th bay is located at $x=x_{s}$, where $0 \leq x_{s}<L$. The sth fastener in the $j$ th bay is located at $x=j L+x_{s}$. A receptance matrix seen by the rail can be defined for the fasteners sharing a slab, and this receptance matrix is used to couple the rail and slabs in the frequency domain. The formulations in Refs. [26-28] allow the rail to be modelled using the two-and-half dimensional finite element method, however, the results presented in this paper are produced with the Timoshenko beam theory. Since the slabs are important only for frequencies up to few hundred hertz, they are modelled based on the thin plate theory using the modal superposition method.

Figure 3 also shows the coordinate system used to describe the track. The origin of the $x$-coordinate is located at the junction between the -1 th and 0 th slab. A vertical harmonic load, $\mathbf{p}_{0} \mathrm{e}^{\mathrm{i} \Omega t}$, on the right rail is moving at speed $c$ along the track. At $t=0$, the load is at $x=x_{0}$. Unlike the wheelset, for the track the harmonic force does not produce a purely harmonic response due to the spatial variation in its properties. 


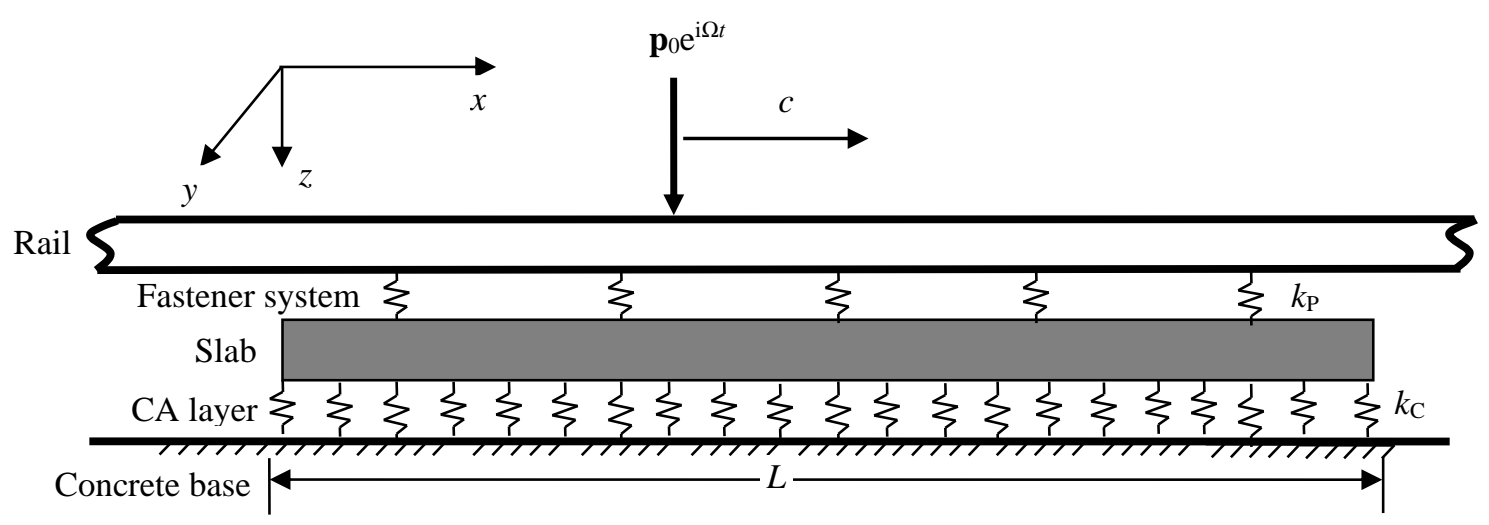

Fig. 3. The slab high-speed railway track and coordinate system used. Only one rail is shown.

\section{Vibrational displacement of the track}

The displacement vector of the two rails and slab at position $x$ and time $t$ is denoted by $\mathbf{q}\left(x, x_{0}, t, \Omega\right)$ (formed by the vertical displacement and rotation angle of the rail when it is modelled as a Timoshenko beam). If observation is made from a reference frame moving with the load, the displacement vector is denoted by $\mathbf{q}\left(x^{\prime}, x_{0}, t, \Omega\right)$, where $x^{\prime}=x-x_{0}-c t$, a coordinate measured from the moving load. It can be shown that the response can be expanded in the form [26-28]

$$
\mathbf{q}\left(x^{\prime}, x_{0}, t, \Omega\right)=\mathbf{Q}\left(x^{\prime}, x_{0}+c t, \Omega\right) \mathbf{p}_{0} \mathrm{e}^{\mathrm{i} \Omega t} .
$$

Equation (1) can be used to calculate the response of a rail at a wheel/rail contact point due to a unit harmonic force at the same or another wheel/rail contact point, laying a basis for dealing with wheel/rail interactions.

By analogy to the case of a stationary harmonic load, the matrix, $\mathbf{Q}\left(x^{\prime}, x_{0}+c t, \Omega\right)$, may be termed the 'receptance' matrix of the track at a position defined by $x$ ', but for the moving load it depends on the excitation frequency $\Omega$ and the load position $x_{0}+c t$. It is shown in Refs. [26-28] that, for a given load frequency $\Omega$, the 'receptance' matrix is not temporally constant, but instead, it is a periodic function of $x_{0}+c t$ with the period of the track structure period, $L$. It can therefore be expressed as a Fourier series, given by

$$
\mathbf{Q}\left(x^{\prime}, x_{0}+c t, \Omega\right)=\sum_{j=-\infty}^{\infty} \tilde{\mathbf{Q}}_{j}\left(x^{\prime}, \Omega\right) \mathrm{e}^{-\mathrm{i} 2 \pi j\left(x_{0}+x^{\prime}+c t\right) / L},
$$

where the Fourier coefficient matrix, $\tilde{\mathbf{Q}}_{j}\left(x^{\prime}, \Omega\right)$, is given by

$$
\tilde{\mathbf{Q}}_{j}\left(x^{\prime}, \Omega\right)=\frac{1}{2 \pi} \int_{-\infty}^{\infty} \hat{\mathbf{Q}}_{j}(\beta, \Omega) \mathrm{e}^{\mathrm{i} \beta x^{\prime}} \mathrm{d} \beta
$$


223 This is an inverse Fourier transform of the matrix $\hat{\mathbf{Q}}_{j}(\beta, \Omega)$ from the wavenumber, $\beta$, in the track 224 direction, to the spatial coordinate, $x^{\prime}$. Detailed expressions for this matrix can be found in Ref. [26] 225 for a conventional ballasted track, in Ref. [27] for a track with rail dampers, and in Ref. [28] for the 226 slab track shown in Fig. 3 (Note: in these references, a unit vertical harmonic force is applied on both 227 rail, and the track vibrates symmetrically. However, the derivations can be easily modified when only 228 one rail is loaded). Thus from Eqs. (2) and (3), one has

$$
\mathbf{q}\left(x, x_{0}, t, \Omega\right)=\sum_{j=-\infty}^{\infty}\left(\frac{1}{2 \pi} \int_{-\infty}^{\infty} \hat{\mathbf{Q}}_{j}(\beta, \Omega) \mathrm{e}^{\mathrm{i}(\beta-2 \pi j / L) x} \mathrm{e}^{\mathrm{i}(\Omega-\beta c) t} \mathrm{e}^{-\mathrm{i} \beta x_{0}} \mathrm{~d} \beta\right) \mathbf{p}_{0} .
$$

\section{Vibrational velocity spectra of the track}

231 The response at a given position $x$ fixed on the track is temporally transient as the load moves, thus 232 a frequency spectrum can be defined as below

$$
\hat{\mathbf{q}}\left(x, x_{0}, f, \Omega\right)=\int_{-\infty}^{\infty} \mathbf{q}\left(x, x_{0}, t, \Omega\right) \mathrm{e}^{-\mathrm{i} 2 \pi f t} \mathrm{~d} t
$$

With Eqs. (4) and (5) it can be shown that,

$$
\hat{\mathbf{q}}\left(x, x_{0}, f, \Omega\right)=\frac{1}{c}\left[\sum_{j=-\infty}^{\infty} \hat{\mathbf{Q}}_{j}\left(\beta^{*}, \Omega\right) \mathrm{e}^{\mathrm{i} \beta_{j} x}\right] \mathrm{e}^{-\mathrm{i} \beta^{*} x_{0}} \mathbf{p}_{0}
$$

where

$$
\beta^{*}=(\Omega-2 \pi f) / c, \quad \beta_{j}=\beta^{*}-2 \pi j / L .
$$

The vibrational velocity spectrum of the track is given simply by the displacement spectrum multiplied by $i 2 \pi f$, i.e.

$$
\hat{\dot{\mathbf{q}}}\left(x, x_{0}, f, \Omega\right)=\frac{\mathrm{i} 2 \pi f}{c}\left[\sum_{j=-\infty}^{\infty} \hat{\mathbf{Q}}_{j}\left(\beta^{*}, \Omega\right) \mathrm{e}^{\mathrm{i} \beta_{j} x}\right] \mathrm{e}^{-\mathrm{i} \beta^{*} x_{0}} \mathbf{p}_{0} .
$$

Thus, for the given moving harmonic load, the vibrational velocity spectrum of the track at spectral frequency $f$ is the sum of an infinite number of travelling waves at frequency $f$. The wavenumber of the $j$ th travelling wave is $\beta_{j}$, given in Eq. (7). Note that the units of the vibrational velocity spectrum $\operatorname{are~}(\mathrm{m} / \mathrm{s}) / \mathrm{Hz}$.

\section{Prediction of wheel/rail interaction}

Figure 4 shows the wheel/rail interaction model used to predict the wheel/rail force. A linear contact spring and a roughness strip (represented by the triangle in Fig. 4) are inserted between each 
wheel and rail in contact. The sign of the rail irregularity is defined as positive if the actual rail surface is at a higher level than the nominal level. The sign of the wheel irregularity is defined as positive if the radius of the wheel is larger than its nominal one. If the displacements of the wheel $\left(w_{l}^{\mathrm{W}}(t)\right)$ and rail $\left(w_{l}^{\mathrm{R}}(t)\right)$ at the $l$ th contact point are directed downwards, then

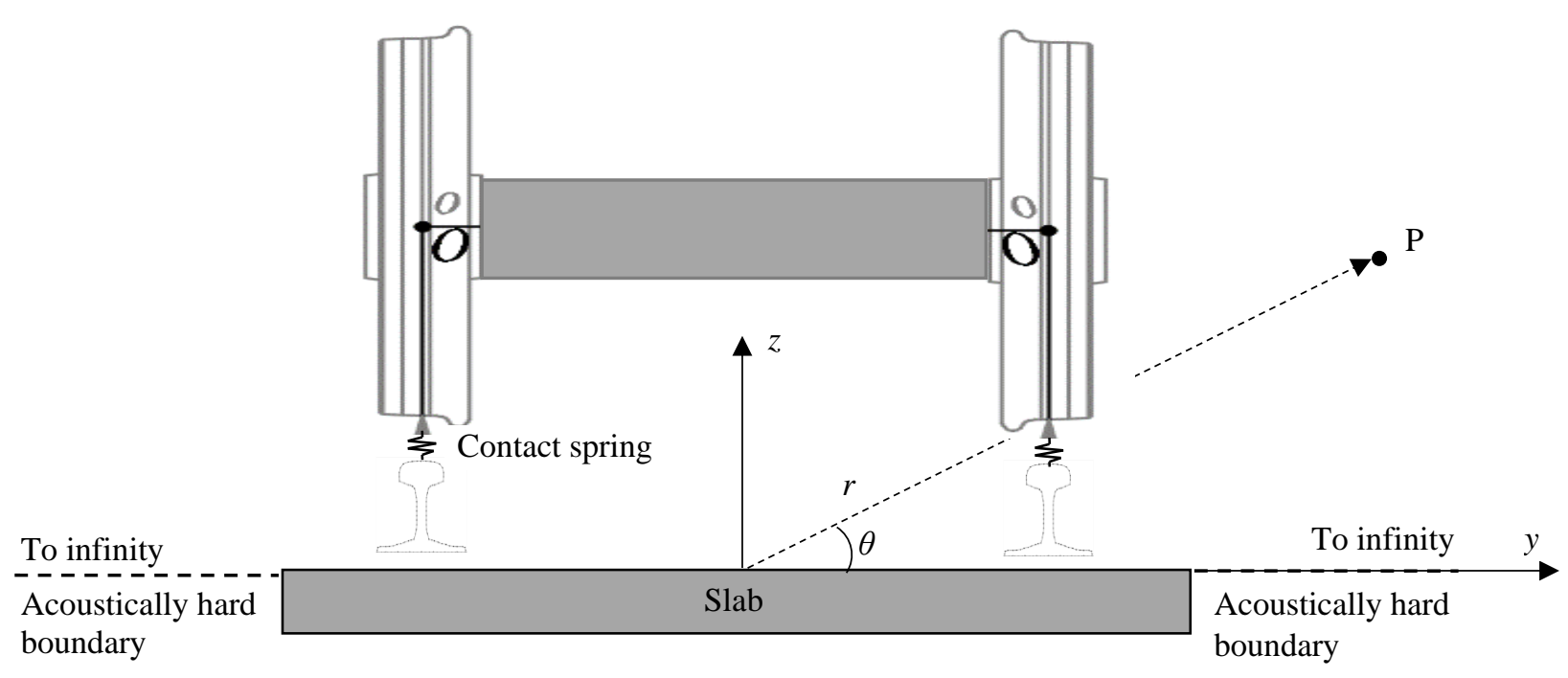

Fig. 4. The wheelset/track system and the acoustic domain.

$$
w_{l}^{\mathrm{W}}(t)-w_{l}^{\mathrm{R}}(t)+z_{l}\left(x_{l 0}+c t\right)=C_{l} P_{l 0}^{2 / 3}+\frac{2}{3} C_{l} P_{l 0}^{-\frac{1}{3}} f_{l}(t),
$$

where $z l(x)$ denotes roughness experienced by the $l$ th wheelset, $x_{l 0}$ is the position of the wheelset at $t$ $=0, P_{l 0}$ is the static component (i.e. half the axle load) of the $l$ th wheel-rail force, $f_{l}(t)$ is the dynamic component and $C_{l}$ is a constant. The equations are valid for roughness that is small enough to avoid loss of contact between the wheel and the rail, and for the approximation of the non-linear Hertzian contact spring by a linear one, of which the receptance is given by $(2 / 3) C_{l} P_{l 0}^{-\frac{1}{3}}$. Eq. (9) shows two excitation mechanisms, one being the roughness $z_{l}\left(x_{l 0}+c t\right)$ and the other being the axle load-related term $C_{l} P_{l 0}^{2 / 3}$. The following method is used to determine $f_{l}(t)$.

To calculate the dynamic components of the wheel/rail forces, the combined wheel/rail roughness experienced by the wheelset is assumed to be periodic in the track direction, with the period being a multiple of the track period. In other words, if the roughness is denoted by $z(x)$, it is assumed that,

$$
z(x+N L)=z(x)
$$

where $N$ is a positive integer. In addition, use is made of the following facts: (1) the track is an infinitely long periodic structure with period $L$ and (2) the receptance of the wheelset at the wheel/rail contact point can be defined (see Section II. A), although it is in rotation. Consequently, the wheel/rail 
force is also temporally periodic with the period being $N L / c$, the time required for the wheelset to traverse one period of the roughness (i.e. $N$ periods of the track). In other words, the wheel/rail force, in addition to the steady axle load, contains components at the fundamental frequency $c /(N L)$ and its harmonics. Here, $f_{\mathrm{S}-\mathrm{P}}=c / L$ is termed the bay-passing frequency. According to Ref. [29], the frequencies of the wheel/rail force can be expressed as $(\sigma+n / N) f_{\text {S-P }}$, with $\sigma=-\Sigma,-(\Sigma-1), \cdots,-1,0,1,2, \cdots, \Sigma$, and $n=0,1, \cdots, N-1$. Here, $\Sigma$ is an integer above which the wheel/rail force frequency components are negligible.

It is shown in Ref. [29] that for each integer $n$, where $0 \leq n \leq N-1$, the wheel/rail force frequency components at frequencies $(\sigma+n / N) f_{\mathrm{S}-\mathrm{P}}$, where $\sigma=-\Sigma,-(\Sigma-1), \cdots,-1,0,1,2, \cdots, \Sigma$, can be determined by solving a set of linear algebraic equations. The number of the linear algebraic equations is $2 \Sigma+1$, and the choice of $\Sigma$ depends on the frequency range considered. For example, for $c=350$ $\mathrm{km} / \mathrm{h}, L=6.5 \mathrm{~m}, N=8$, the fundamental frequency of the wheel/rail force is about $1.87 \mathrm{~Hz}$. If the considered frequency range extends up to $5 \mathrm{kHz}$, then $\Sigma$ is around 333 .

The above method, termed the Fourier-series method in Ref. [29], is not suitable for calculating wheel/rail forces generated by wheel/rail impacts such as when a wheel rolls over a rail indentation or a wheel flat. Wheel/rail separation may occur during the impact. In this case, wheel/rail forces may be predicted using a method based on the so-called time domain moving Green's function of the railway track [30-32].

\section{Prediction of wheel radiation}

To predict sound radiation from a wheelset and the track, an acoustic domain must be first defined. For a slab high-speed railway in an open space, the acoustic domain may be approximated to be a half-space, as shown in Fig. 4. The horizontal surface beyond the slab is assumed to be acoustically hard. Other boundaries of the acoustic domain are radiating, including the top surface of the slab, the surface of the two rails, and the surface of the wheelset. To simplify the prediction of sound radiation from the track, connections between the rails and the slab are removed in the acoustic calculation, leaving a uniform gap between the rail and the slab (the effect of this simplification will be discussed in Section III.E.1). The presence of the train body is also neglected in the current model. To compensate for this, rolling noise is calculated only for the wheel (or wheels) and rail on the righthand side, although the entire slab is taken into account for simplicity. For the track sound radiation, the presence of the wheelset is ignored, and thus the boundaries of the acoustic domain are infinitely long and uniform in the track direction. Fig. 4 also shows the coordinate system for the sound field. An observation point $\mathrm{P}$ is defined in cylindrical coordinates by a radial distance $r$ and an angle $\theta$ with the origin at the track centre line on the top surface of the slab. 
In this step (prediction of wheel acoustics), the sound pressure spectrum generated by the vibration of the wheelset predicted in Section II.A is calculated. From Section II.A, for a harmonic load rotating about the wheelset axis, the response of each point on the wheelset in the frame of reference fixed with respect to the wheel/rail contact point is also harmonic, although the response in the frame rotating with the wheel is not.

Sound is radiated by the normal velocity of the wheelset surface. By neglecting the aerodynamic effects caused by wheel rotation and motion, and assuming a sliding boundary condition on the surface of the wheel, it can be concluded that the particle velocity of the air in contact with the wheelset surface is equal to the normal velocity of the wheelset and is, therefore, also harmonic at the same frequency. However, for an observation point fixed relative to the ground, although the wheel is vibrating harmonically, it forms a moving noise source; the sound field will therefore be modified by the Doppler Effect. For a high-speed train, the Mach number can be as high as 0.3 and this effect can be significant and should be taken into account.

Consequently, for a high-speed train, the prediction of the sound field generated by a moving and vibrating object is an important topic. By making use of sound spectra generated by moving harmonic compact sources (a monopole and a dipole), three-dimensional boundary integral equations are established in Ref. [33] for the prediction of sound radiated from a harmonically vibrating body moving uniformly in a free space. Currently, however, a numerical tool is still to be developed to solve this boundary integral equation. Thus, the following approximate method is used in this paper.

First, the sound power of the wheelset is calculated in the frame of reference moving with the train. In this frame of reference, apart from its rotation the wheelset is stationary and vibrates harmonically, and its sound radiation can be predicted using a conventional vibro-acoustic method such as the frequency domain acoustic boundary element method. For the sound radiation from a wheelset the rails are neglected but the rigid ground is taken into account by including an image source. Hence both the wheelset and its image are located in a full space. Considering the distance between the centre of the wheel and that of the image source, for frequencies above about $150 \mathrm{~Hz}$, the effect of the image on sound radiation of the actual wheelset can be neglected. Thus, a 2.5D acoustic boundary element method, which only requires a 2D boundary mesh, can be derived for calculating the sound pressure in each circumferential order, as described in Ref. [34]. In this way, the sound power radiated by the wheelset can be obtained. The total sound power is the sum of sound powers due to each circumferential order [34].

Then the right-hand wheel is simplified as a monopole source moving uniformly in the direction of the track (or a combination of a monopole and a dipole, as done in TWINS. However, for simplicity, only a monopole is used in this paper). This point source, located at the wheel centre, is assumed to 
pulsate at the same frequency as the wheel/rail force. The sound power radiated by the point source is obtained from the above calculation for the wheel, from which the volume velocity amplitude, $\tilde{Q}$ (in units $\mathrm{m}^{3} / \mathrm{s}$ ), of the point source can be determined by [35]

$$
|\tilde{Q}|^{2}=\frac{8 \pi c_{0} W}{\rho_{0} \Omega^{2}}
$$

where $\Omega$ is the frequency of the source, $W$ is the calculated sound power, and $\rho_{0}$ and $c_{0}$ denote air density and sound speed, respectively. From Eq. (11) only the magnitude of the volume velocity is determined, without phase information.

It is further assumed that, at time $t=0$, the point source is located at $\left(x_{0}, y_{0}, z_{0}\right)$. The sound pressure produced at $(x, y, z)$ by this moving point source is temporally transient, although the source itself is temporally harmonic. Therefore it is denoted by $g\left(x, y, z ; x_{0}, y_{0}, z_{0} ; \Omega ; t\right)$. Its frequency spectrum, denoted by $\hat{g}\left(x, y, z ; x_{0}, y_{0}, z_{0} ; \Omega ; f\right)$, is defined through the following Fourier transform,

$$
\hat{g}\left(x, y, z ; x_{0}, y_{0}, z_{0} ; \Omega ; f\right)=\int_{-\infty}^{\infty} g\left(x, y, z ; x_{0}, y_{0}, z_{0} ; \Omega ; t\right) \mathrm{e}^{-\mathrm{i} 2 \pi f t} \mathrm{~d} t
$$

For the point source moving at speed $c$ in the $x$-direction in the full space, the sound pressure frequency spectrum is given by [33],

$$
\hat{g}\left(x, y, z ; x_{0}, y_{0}, z_{0} ; \Omega ; f\right)=\frac{\mathrm{i} \rho_{0} \tilde{Q} 2 \pi f}{c} \tilde{G}\left(\beta, y, z ; y_{0}, z_{0}\right) \mathrm{e}^{\mathrm{i} \beta\left(x-x_{0}\right)}
$$

where $i=\sqrt{-1}$,

$$
\tilde{G}\left(\beta, y, z ; y_{0}, z_{0}\right)=\frac{1}{2 \pi} K_{0}(\kappa r) .
$$

with $K_{0}(\cdot)$ being the modified Bessel functions of order zero of the second kind, and

$$
\begin{aligned}
& r=\sqrt{\left(y-y_{0}\right)^{2}+\left(z-z_{0}\right)^{2}}, \\
& \kappa=\sqrt{\beta^{2}-k_{0}^{2}}, \\
& \beta=(\Omega-2 \pi f) / c \\
& k_{0}=2 \pi f / c_{0} .
\end{aligned}
$$

The sound pressure frequency spectrum of the moving point source (representing the wheel) in the half-space can be obtained based on the image source method, i.e. 


$$
\hat{g}\left(x, y, z ; x_{0}, y_{0}, z_{0} ; \Omega ; f\right)=\frac{\mathrm{i} \rho_{0} \tilde{Q} 2 \pi f}{c}\left[\tilde{G}\left(\beta, y, z ; y_{0}, z_{0}\right)+\tilde{G}\left(\beta, y, z ; y_{0},-z_{0}\right)\right] \mathrm{e}^{\mathrm{i} \beta\left(x-x_{0}\right)},
$$

and this is termed the wheel sound transfer function, denoted by $\operatorname{WSTF}\left(f, \Omega, x_{0}\right)$.

\section{E. Prediction of track radiation}

Under the action of the moving harmonic load shown in Fig. 3, the sound pressure received at a given position in the acoustic domain is also transient. It is the sum of that generated from slab vibration and that from rail vibration. These two sound pressure components may be computed separately.

In Section II.B, the vibration spectrum at spectral frequency $f$ of the track due to the unit moving harmonic load (at a radian frequency $\Omega$ ) on each rail (symmetrically or anti-symmetrically) has been expressed as the sum of an infinite number of harmonic travelling waves. Thus the sound pressure spectrum at a given position in the field can be calculated as the sum of those generated by individual travelling waves.

\section{Sound generated by a harmonic travelling wave in the slab}

For sound radiation by the slab vibration, the two rails may be omitted to simplify the acoustic domain. The sound pressure at a given location in the acoustic domain is predicted for a slab vibrational velocity wave defined by

$$
\phi_{j}(x, y, t)=\Phi_{j}(y) \mathrm{e}^{\mathrm{i} 2 \pi f t} \mathrm{e}^{-\mathrm{i} \beta x},
$$

at a range of discrete spectral frequencies $(f)$ and wavenumbers $(\beta)$, where $\Phi_{j}(y)(j=1,2, \ldots)$ is the $j$ th shape function with which variation of the slab velocity spectrum in the $y$-direction can be synthesised. This will generate a number of so-called Slab Sound Transfer Functions (SSTF). The $\operatorname{SSTF}$ for $\Phi_{j}(y)$ is denoted by $\operatorname{SSTF}_{j}(f, \beta)$.

Owing to the fact that the acoustic domain is uniform in the track direction, the sound field induced by the vibrational wave defined in Eq. (20) has the same form as that equation, i.e.

$$
p_{j}(x, y, z, t)=\tilde{p}_{j}(\beta, y, z) \mathrm{e}^{\mathrm{i} 2 \pi f t} \mathrm{e}^{-\mathrm{i} \beta x} .
$$

Since the acoustically hard boundaries of the acoustic domain are infinite in the lateral direction, the slab is equivalent to a baffled plate that is infinitely long in the $x$-direction. Its sound radiation may be calculated using the following integral equation which is derived from the classic Rayleigh integral equation, 


$$
\tilde{p}_{j}(\beta, y, z)=2 f \rho_{0} \mathrm{i} \int_{-0.5 b_{\mathrm{S}}}^{0.5 b_{\mathrm{S}}} \Phi_{j}\left(y^{\prime}\right) K_{0}(\kappa r) \mathrm{d} y^{\prime},
$$

where $\rho_{0}$ is air density, $b_{\mathrm{s}}$ is the width of the slab, $K_{0}(\cdot)$ is the modified Bessel function of the 0th order and the second kind, $r=\sqrt{\left(y-y^{\prime}\right)^{2}+z^{2}}, \quad \kappa=\sqrt{\beta^{2}-k_{0}^{2}}, k_{0}=2 \pi f / c_{0}$ is the acoustic wavenumber, and $c_{0}$ is sound speed in air.

\section{Sound generated by a harmonic travelling wave in a rail}

For sound radiation from the vibration of a rail, the slab can be assumed to be acoustically hard if no acoustic treatment is made to its upper surface. As for the slab, a number of so-called Rail Sound Transfer Functions (RSTF) may be obtained for waves (in terms of normal velocity) defined by

$$
\varphi_{k}(x, s, t)=\Psi_{k}(s) \mathrm{e}^{\mathrm{i} 2 \pi f t} \mathrm{e}^{-\mathrm{i} \beta x},
$$

at a range of discrete spectral frequencies $(f)$ and wavenumbers $(\beta)$, where $\Psi_{k}(s)(k=1,2, \ldots)$ is the $k$ th shape function which is employed to synthesize the vibrational variation along the periphery (described by the distance $s$ ) of the rail cross-section. If the Timoshenko beam theory is used to describe the rail, the normal velocity of the rail surface can be readily determined from the vibrational velocity of the rail axis by projecting it onto the rail cross-section. In this case, only one shape function is required. The $\operatorname{RSTF}$ for $\Psi_{k}(s)$ is denoted by $\operatorname{RSTF}_{k}(f, \beta)$. The sound field generated can be described by

$$
p_{k}(x, y, z, t)=\tilde{p}_{k}(\beta, y, z) \mathrm{e}^{\mathrm{i} 2 \pi f t} \mathrm{e}^{-\mathrm{i} \beta x}
$$

in which $\tilde{p}_{k}(\beta, y, z)$ can be determined using the $2.5 \mathrm{D}$ acoustic boundary element method $[28,36]$. To avoid modelling the infinitely wide acoustically hard boundaries shown in Fig. 4 in the 2.5D BEM model, predictions may be performed for the sources shown in Fig. 5 in the full space, based on the image source method.

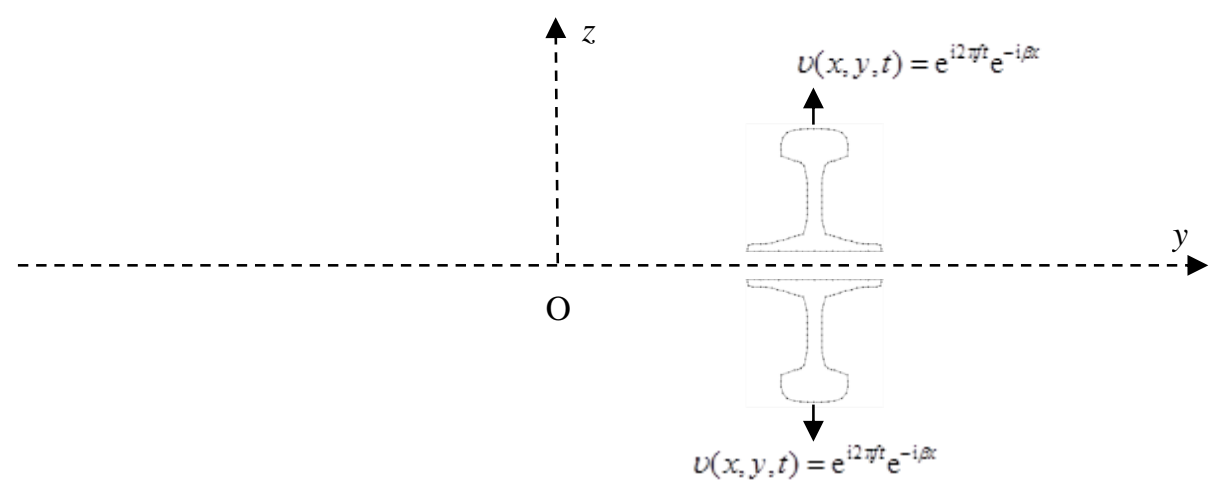

Fig. 5. Sources in the full space generating the same sound field as that produced by a rail in a half-space. 


\section{F. Prediction of wheel/rail rolling noise}

\section{When a single wheelset is considered}

Discussion is first given to the case in which only a single wheelset is considered. At $t=0$, the wheelset is at $x_{0}$. As stated in Section II.C above, the wheel/rail force, in addition to the steady axle load, contains components at a fundamental frequency $f_{0}=c /(N L)$ and its harmonics. The $k$ th harmonic component is denoted by $\tilde{P}_{k} \mathrm{e}^{\mathrm{i} k f_{0} t}$ (the component with $k=0$ is equal to half the axle load). Under the action of this harmonic component, the vertical vibrational velocity spectrum of the slab, according to Eq. (8), may be written as

$$
v_{\mathrm{S} k}\left(x, y, f, x_{0}\right)=\left[\sum_{j=-\infty}^{\infty} \sum_{m=1}^{\infty} \lambda_{k m} \Phi_{m}(y) \mathrm{e}^{\mathrm{i} \beta_{k j} x}\right] \mathrm{e}^{-\mathrm{i} \beta_{k}^{*} x_{0}} \tilde{P}_{k},
$$

where

$$
\beta_{k}^{*}=2 \pi\left(k f_{0}-f\right) / c, \quad \beta_{k j}=\beta_{k}^{*}-2 \pi j / L,
$$

and $\lambda_{k m}$ is a coefficient denoting the contribution of 'mode' $\Phi_{m}(y)$ to the spectrum. Thus, the sound pressure spectrum due to the slab subject to the $k$ th harmonic component of the force is given by

$$
\hat{p}_{\mathrm{S} k}\left(f, x_{0}\right)=\left[\sum_{j=-\infty}^{\infty} \sum_{m=1}^{\infty} \lambda_{k m} \operatorname{SSTF}_{k}\left(f,-\beta_{k j}\right)\right] \mathrm{e}^{-\mathrm{i} \beta_{k}^{*} x_{0}} \tilde{P}_{k} .
$$

Note that the minus sign before $\beta_{k j}$ in Eq. (27) is due to the definition of SSTF.

Similarly, the sound pressure spectrum due to the rail subject to the $k$ th harmonic component of the wheel/rail force is given by

$$
\hat{p}_{\mathrm{R} k}\left(f, x_{0}\right)=\left[\sum_{j=-\infty}^{\infty} \sum_{m=1}^{\infty} \mu_{k m} R \operatorname{STF}_{k}\left(f,-\beta_{k j}\right)\right] \mathrm{e}^{-\mathrm{i} \beta_{k}^{*} x_{0}} \tilde{P}_{k} .
$$

where $\mu_{k m}$ is a coefficient showing the contribution of 'mode' $\Psi_{k}(s)$ (see Eq. (23)) in the vibrational velocity spectrum of the rail.

The sound pressure spectrum due to the wheel subject to the $k$ th harmonic component is given by

$$
\hat{p}_{\mathrm{w} k}\left(f, x_{0}\right)=\operatorname{WSTF}\left(f, \Omega_{k}, x_{0}\right) \tilde{P}_{k},
$$

where $\Omega_{k}=2 \pi k f_{0}$.

Now the total sound pressure spectrum due to the $k$ th harmonic component of the wheel/rail force is calculated to be the incoherent sum of those from the wheel and the track. The reason that the sound 
pressure spectrum from the wheel is added incoherently to that from the track is due to the approximation of sound radiation from the wheel. The total sound pressure spectrum, $\hat{p}\left(f, x_{0}\right)$, due to all the wheel/rail force harmonic components, is then calculated as the incoherent sum of those due to individual harmonic components, i.e.

$$
\left|\hat{p}\left(f, x_{0}\right)\right|^{2}=\sum_{k}\left(\left|\hat{p}_{\mathrm{w} k}\left(f, x_{0}\right)\right|^{2}+\left|\hat{p}_{\mathrm{R} k}\left(f, x_{0}\right)+\hat{p}_{\mathrm{S} k}\left(f, x_{0}\right)\right|^{2}\right) .
$$

\section{When multiple wheelsets are considered}

As shown in Refs. [29, 37, 38], interactions between multiple wheelsets via the track can have a great effect on the wheel/rail forces. However, according to Ref. [29], a wheel/rail force can still be decomposed into harmonic components with $f_{0}$ being the fundamental frequency. The $k$ th harmonic component at the $l$ th wheel is denoted by $\tilde{P}_{l k} \mathrm{e}^{\mathrm{i} k f_{0} t}$. The initial $x$-coordinate of the $l$ th wheelset is denoted by $x_{l 0}$. The total sound pressure spectrum is given by

$$
|\hat{p}(f)|^{2}=\sum_{k} \sum_{l}\left(\left|\hat{p}_{\mathrm{W} l k}\left(f, x_{l 0}\right)\right|^{2}+\left|\hat{p}_{\mathrm{R} l k}\left(f, x_{l 0}\right)+\hat{p}_{\mathrm{S} l k}\left(f, x_{l 0}\right)\right|^{2}\right),
$$

where $\hat{p}_{\mathrm{w} l k}\left(f, x_{l 0}\right)$ denotes the sound pressure spectrum generated by the $l$ th wheel subject to the $k$ th harmonic component in the $l$ th wheel/rail force.

\section{RESULTS}

Results are produced in this section for a typical high-speed train/track system using the approach described above. Measured roughness and pass-by noise and other information are available for this train/track system, making a comparison between prediction and measurement possible, although the measurement was not performed specifically for the purpose of validating the prediction model. This section is divided into five sub-sections A-E. Section A lists the parameters of the wheelset and track, together with a description of the wheel/rail roughness used for the prediction. As has been pointed out, wheel/rail forces are calculated based on the receptances of the wheelset and track and these receptances are shown in Section B. Predicted wheel/rail forces are presented in Section C. To investigate acoustic characteristics of a wheelset rotating at different speeds, the sound power radiated by the wheelset due to a unit vertical harmonic load at the wheel/rail contact points is discussed in Section D. In Section E, the rolling noise is predicted and compared with the measured pass-by noise. The dependence of the noise level on train speed, and the relative contributions of the sound pressure levels generated by the wheel, rail and slab for different train speeds, are also presented in this section. 


\section{A. Wheelset and track parameters}

The cross-section of the wheelset considered in this paper is shown in Fig. 6 with a finite element mesh. The mass of the wheelset is $1105 \mathrm{~kg}$, the running radius is $0.43 \mathrm{~m}$, and the static load applied by the wheelset to each rail is $78.4 \mathrm{kN}$ (i.e. the axle load is $156.8 \mathrm{kN}$ ). Material density is $7850 \mathrm{~kg} / \mathrm{m}^{3}$, Young's modulus is $210 \mathrm{GPa}$ and Poisson's ratio is 0.3 . The damping loss factor used for the wheelset is dependent on the circumferential order, being 0.002 when the circumferential order is zero, 0.02 when the circumferential order is \pm 1 , and 0.0008 for other circumferential orders. Although the latter value is higher than recommended in Ref. [5], it is suitable for the frequency spacing used and is still smaller than the apparent damping that is present during rolling due to coupling with the rail [5].

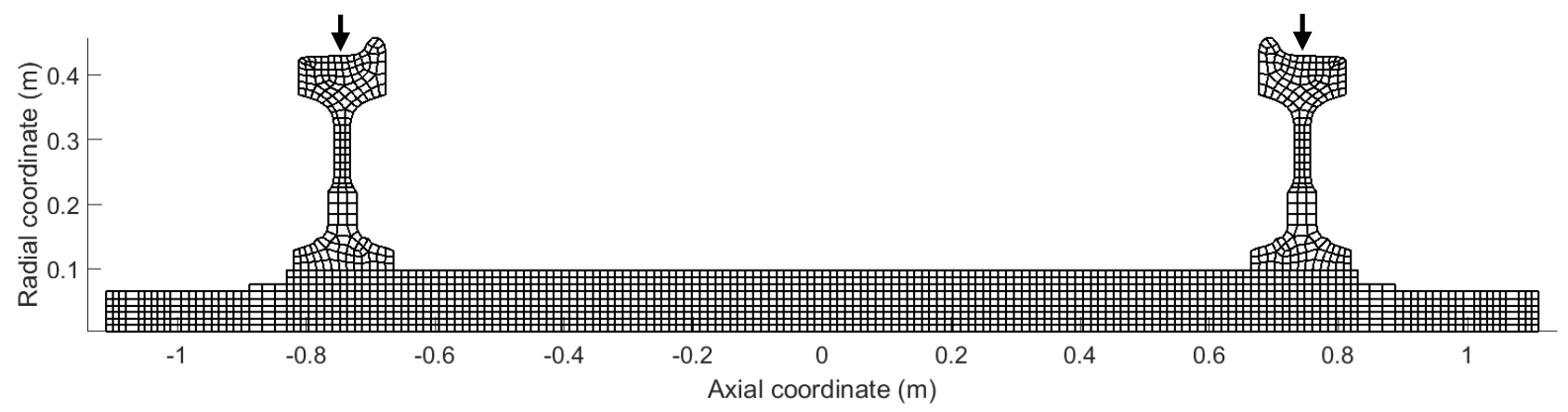

Fig. 6. The wheelset and FE mesh.

For the track, parameters typical of the Chinese CRTS II track are used and listed in Table 1. They are estimated from design documents, in-situ frequency response function measurements and laboratory experiments. 
TABLE 1 Parameters for the vertical dynamics of the track

\begin{tabular}{ll}
\hline Density of the rail & $\rho=7850 \mathrm{~kg} / \mathrm{m}^{3}$ \\
Young's modulus of the rail & $E=2.1 \times 10^{11} \mathrm{~N} / \mathrm{m}^{2}$ \\
Poisson's ratio of the rail & 0.3 \\
Cross-sectional area of the rail & $A=7.69 \times 10^{-3} \mathrm{~m}^{2}$ \\
Second moment of area of the rail & $I=30.55 \times 10^{-6} \mathrm{~m}^{4}$ \\
Shear coefficient of the rail cross-section & $\kappa=0.4$ \\
Distance between the rail bottom and the slab & $0.1 \mathrm{~m}$ \\
Vertical rail pad stiffness & $k_{\mathrm{P}}=5.44 \times 10^{7} \mathrm{~N} / \mathrm{m}$ \\
Rail pad damping loss factor & $\eta_{\mathrm{P}}=0.2$ \\
Sleeper spacing & $d=0.65 \mathrm{~m}$ \\
Period of the track & $L=6.5 \mathrm{~m}$ \\
Length of the slab & $L_{S}=6.45 \mathrm{~m}$ \\
Width of the slab & $b_{S}=2.55 \mathrm{~m}$ \\
Thickness of the slab & $h_{S}=0.2 \mathrm{~m}$ \\
Young's modulus of the slab & $E_{S}=3.45 \times 10^{10} \mathrm{~N} / \mathrm{m}^{2}$ \\
Poisson's ratio of the slab & $v_{S}=0.2$ \\
Density of the slab & $\rho_{S}=2500 \mathrm{~kg} / \mathrm{m}^{3}$ \\
Vertical stiffness of the CA layer & $k_{C}=6.67 \times 10^{9} \mathrm{~N} / \mathrm{m}^{3}$ \\
Damping loss factor of the CA layer & $\eta_{C}=0.1$ \\
\hline
\end{tabular}

To predict the rolling noise for train speeds between $200 \mathrm{~km} / \mathrm{h}$ and $400 \mathrm{~km} / \mathrm{h}$ and for frequencies between $20 \mathrm{~Hz}$ and $5000 \mathrm{~Hz}$, roughness with wavelengths between about $5 \mathrm{~m}$ and $0.01 \mathrm{~m}$ is required. 480 The roughness spectrum used, expressed in terms of the 1/3 octave wavelength bands, is a synthesis 481 of a measured roughness spectrum for centre wavelengths shorter than $0.5 \mathrm{~m}$ and the ORE (ERRI) 482 spectrum [39] for centre wavelengths longer than $2 \mathrm{~m}$. For centre wavelengths between $0.5 \mathrm{~m}$ and 2 $\mathrm{m}$, the spectrum level in $\mathrm{dB}$ is assumed to be linearly dependent on wavelength. To predict wheel/rail forces, the broadband spectrum must be converted into a narrow-band spectrum. It is well known that wheel/rail contact patch has a filtering effect for the roughness. The actual roughness in $\mathrm{dB}$ re $1 \mu \mathrm{m}$ should be modified by a filter characteristic $L_{z}(\lambda)$, which is a function of wavelength. An approximation of $L_{z}(\lambda)$ is given in Ref. [5] as,

$$
L_{z}(\lambda)=20 \log _{10}\left(1+0.25 \pi(2 \pi a / \lambda)^{3}\right)
$$

490 For the wheel, rail and normal load considered here, $a$ is estimated to be $6.72 \mathrm{~mm}$. The roughness 491 after considering the filtering effect is shown in Fig. 7. 
A phase angle, which is assumed to be uniformly distributed over $[0,2 \pi]$, is generated 493 independently for each component of the roughness spectrum.

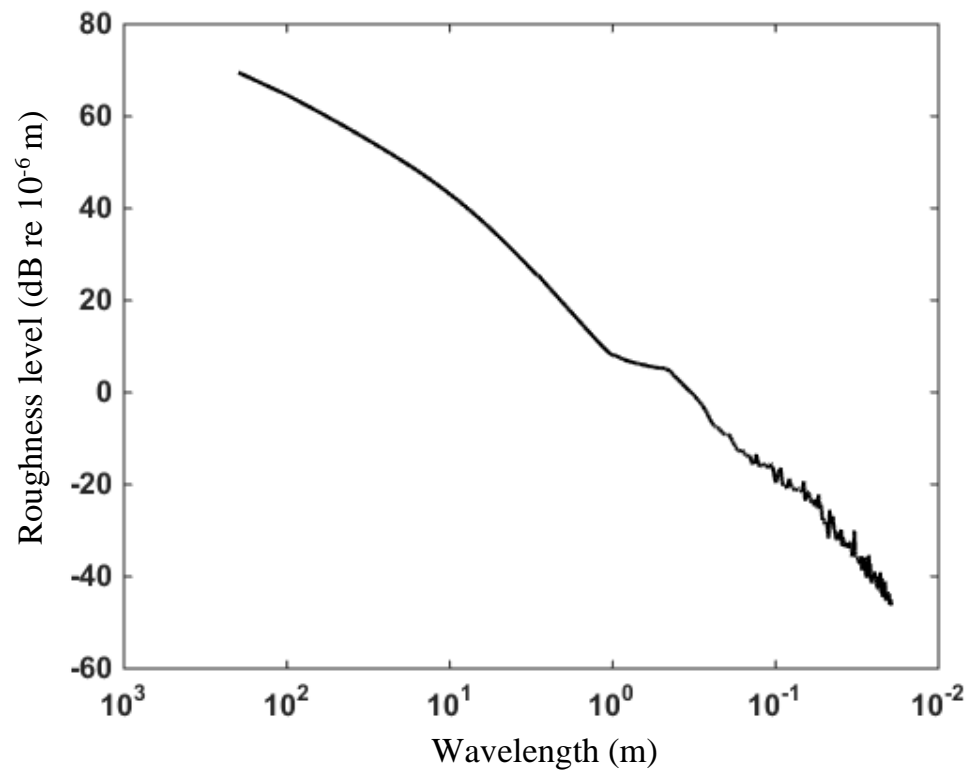

Fig. 7. Wheel/rail roughness.

\section{B. Wheelset and track receptances at the wheel/rail contact point}

The vertical receptance of the wheelset at the wheel/rail contact point is shown in Fig. 8 for three cases. It should be pointed out that, here the term receptance for the wheelset and rail is actually the displacement due to two unit forces applied symmetrically. Two observations can be made: 1) for frequencies lower than about $68 \mathrm{~Hz}$ (the first bending natural frequency of the wheelset), the wheelset behaves like a rigid body of the same mass $m_{\mathrm{w}}$, of which the receptance at frequency $f$ can be calculated to be $\left.2 /\left[(2 \pi f)^{2} m_{\mathrm{W}}\right] ; 2\right)$ when the wheelset is in rotation, peaks at natural frequencies of the non-rotating wheelset are split into pairs of peaks with a smaller amplitude, and these peaks are still as sharp as the original one. This is a combined effect of the moving load and gyroscopic (Coriolis) force [25]. These two peaks occur at $\omega_{m}^{0}+\Delta \omega^{+}-m \Omega_{y}$ and $\omega_{m}^{0}-\Delta \omega^{-}+m \Omega_{y}$, where $\omega_{m}^{0}$ is the natural frequency of the non-rotating wheelset at nodal diameter number $m, \Omega_{y}$ is the rotational speed in $\mathrm{rad} / \mathrm{s}$, and $\Delta \omega^{-}$and $\Delta \omega^{+}$are differences in natural frequency at nodal diameter $m$ between the rotating wheelset and the non-rotating wheelset. Due to rotation, the non-rotating natural frequency $\omega_{m}^{0}$ will become two, one lower, and the other higher, than $\omega_{m}^{0}$. The lower one is given by $\omega_{m}^{-}=\omega_{m}^{0}-\Delta \omega^{-}$and the higher one given by $\omega_{m}^{+}=\omega_{m}^{0}+\Delta \omega^{+}$. 


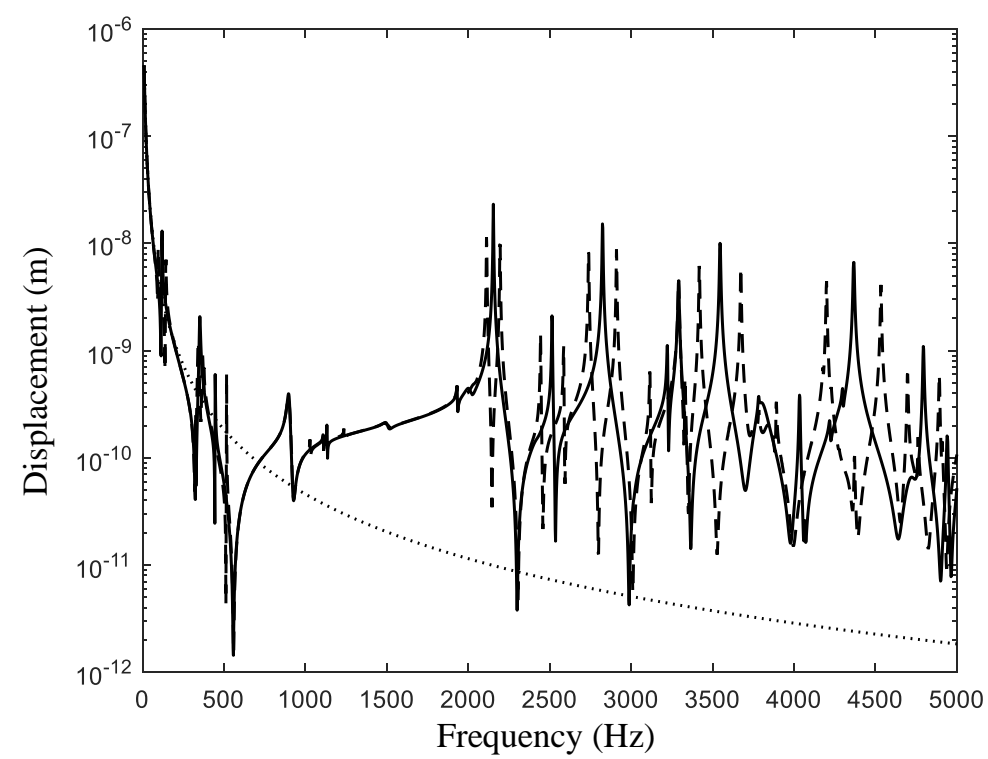

Fig. 8. Receptance of the wheelset at the wheel/rail contact point (symmetric loading). _ _ , wheelset not in rotation; -- , wheelset rotating at $350 \mathrm{~km} / \mathrm{h} ; \cdots \cdots$, wheelset as a rigid body.

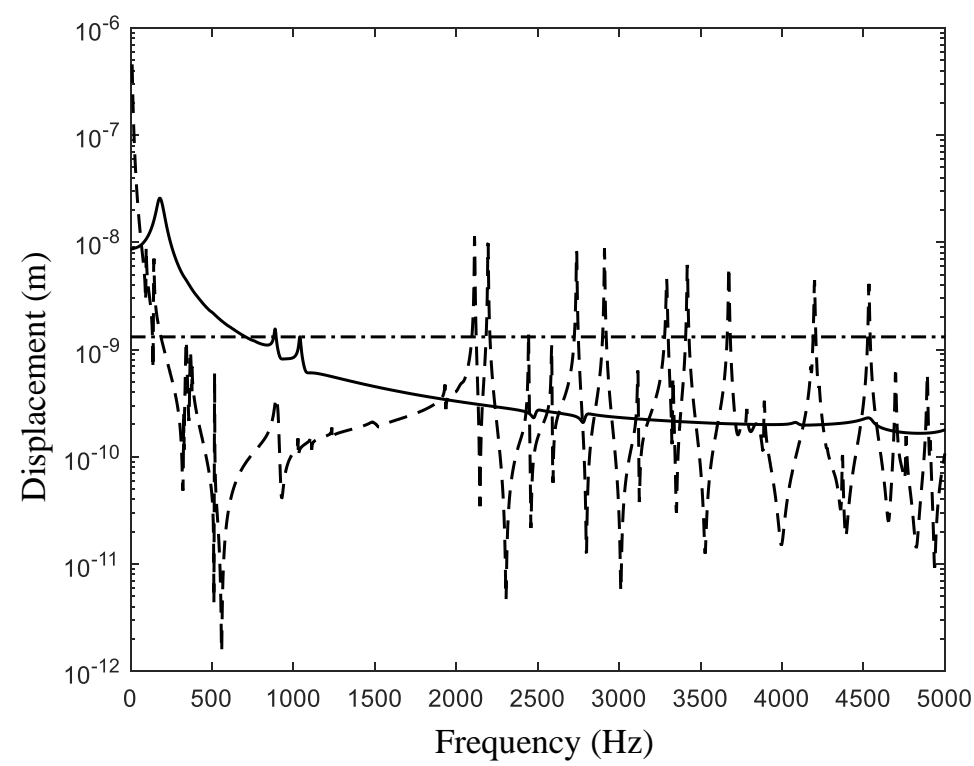

Fig. 9. Receptance at the wheel/rail contact point (symmetric loading). _ _ rail with the force moving at $350 \mathrm{~km} / \mathrm{h}$; -- , wheelset rotating at $350 \mathrm{~km} / \mathrm{h} ;-\cdot-$, contact spring.

The receptances of the wheelset, rail and contact spring due to symmetric loading (each wheel/rail contact point is subjected to a unit vertical force in the same direction) is shown in Fig. 9. The load speed is $350 \mathrm{~km} / \mathrm{h}$. The horizontal dash-dotted line represents the receptance of the contact spring. For the rail, the 'receptance' (see Eq. (1)) is calculated as the displacement amplitude of the rail at $t$ $516=0$ when the load is just above the interface of two adjacent slabs (also at the mid-span between two fasteners).

Since the rail pads are rather soft and the slab is quite stiff, the rail behaves dynamically as if it were supported by fasteners on a rigid foundation. The peak in the rail receptance at about $180 \mathrm{~Hz}$ 
corresponds to the resonance of the rail mass on the stiffness of the fasteners, which is the cut-on frequency for wave propagation in the rail. At the cut-on frequency the rail wavenumber is small and the response still has quite a large decay rate. Although the load moves at $350 \mathrm{~km} / \mathrm{h}$, this peak therefore does not split into two. However, it is shifted to a slightly lower frequency and the peak is flattened to some extent by the moving load, if compared with the case of a stationary load. Conversely, the peak at the fundamental pinned-pinned frequency (about $940 \mathrm{~Hz}$ ) and the dip at the second pinned-pinned frequency (about $2580 \mathrm{~Hz}$ ) are split into two peaks or dips by the moving load.

The receptance of the rail is equal to that of the wheel at about $66 \mathrm{~Hz}$, and at this frequency the contact spring is much stiffer; this frequency is often called the P2-resonance and corresponds to the resonance of the wheelset mass on the dynamic stiffness provided to the wheelset by the track.

Four frequency regions can be identified in Fig.9. In the first region, below $66 \mathrm{~Hz}$, the wheelset has a much higher receptance than the rail and the contact spring. For frequencies in the second region, between 66 and $1000 \mathrm{~Hz}$, the rail has a much higher receptance than the wheelset and the contact spring. In the third region, between 1000 and $2000 \mathrm{~Hz}$, the contact spring is dynamically the softest. Finally, for frequencies higher than about $2000 \mathrm{~Hz}$, the receptance peaks of the wheelset are much higher than the receptances of the rail and contact spring at the corresponding frequency.

\section{Sound power radiated from the wheelset subject to unit vertical harmonic forces}

Figure 10 shows the sound power level in $\mathrm{dB}\left(\mathrm{re} 10^{-12} \mathrm{~W}\right.$ ) radiated by one of the wheels (the wheelset is subject to a unit vertical harmonic force at each wheel/rail contact point). Two rotation speeds are considered, $250 \mathrm{~km} / \mathrm{h}(25.7 \mathrm{~Hz})$ and $350 \mathrm{~km} / \mathrm{h}(36 \mathrm{~Hz})$. Peaks in the radiated sound power are caused by resonances of the rotating wheelset. To show this more clearly, the receptance of the rotating wheelset at the wheel/rail contact point at $350 \mathrm{~km} / \mathrm{h}$ is also plotted in dotted line in $\mathrm{dB}$ (re $10^{-9} \mathrm{~m}$ ). It can be seen that a peak in receptance always corresponds to a peak in sound power.

From Fig. 10 it can be seen that, the wheel radiates sound much more effectively for frequencies higher than about $2000 \mathrm{~Hz}$. Wheel rotation changes the frequencies where the sound power level peaks, but does not change the heights of the peaks significantly. However, as shown in Fig. 8, wheel rotation can split a peak into two peaks which are well separated and as sharp as the original one. If one of the two peaks is in a 1/3-octave band different from the one in which the original peak is located, then differences in the 1/3-octave band result may be predicted between a rotating wheel and a non-rotating wheel. 


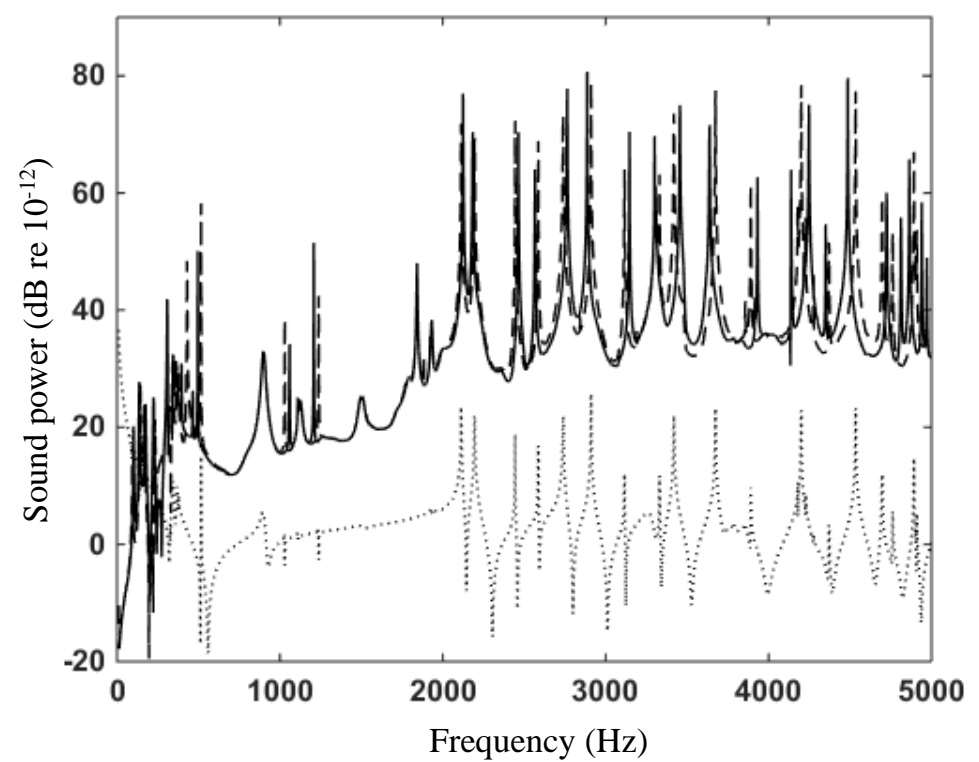

Fig.10. Sound power radiated by a wheel (the wheelset is subject to a unit vertical harmonic force at each wheel/rail contact point). ——, $250 \mathrm{~km} / \mathrm{h} ;---, 350 \mathrm{~km} / \mathrm{h} ; \cdots \cdots$, wheelset receptance $\left(\mathrm{dB}\right.$ re $\left.10^{-9}\right)$ at $350 \mathrm{~km} / \mathrm{h}$.

\section{Wheel/rail forces}

Wheel/rail forces are produced for two speeds, $250 \mathrm{~km} / \mathrm{h}$ and $350 \mathrm{~km} / \mathrm{h}$, using the Fourier-series method described in Section II.C (for more details see Ref. [29]). According to this method, the wheel/rail roughness must be assumed to be periodic and the period is a multiple of the period of the track. Since the roughness is periodic, it can be expressed as a Fourier series. Terms of the Fourier series are determined based on the spectrum shown in Fig. 7.

According to the Fourier-series method, wheel/rail forces are generated only at discrete frequencies given by $f_{k}=k c /(N L)$, where $k$ is an integer, $c$ is train speed, $L$ is the length of a slab and $N L$ is the period of the roughness. Here $N$ is taken to be 6 for $250 \mathrm{~km} / \mathrm{h}$, producing a frequency resolution of $1.78 \mathrm{~Hz}$ for the wheel/rail force. For $350 \mathrm{~km} / \mathrm{h}, N$ is set to be 8 and the frequency resolution is $1.87 \mathrm{~Hz}$.

\section{Due to a single wheelset}

The wheel/rail force due to a single wheelset is shown in Fig. 11 for $250 \mathrm{~km} / \mathrm{h}$ and $350 \mathrm{~km} / \mathrm{h}$. A peak at about $66 \mathrm{~Hz}$ is indicated in the figure as Peak A. This is the P2 resonance mentioned in Section III.B. A dip at about $180 \mathrm{~Hz}$ is also noted in the figure as Dip B. Since these frequencies are rather low, these two features may be explained by the moving roughness wheel/rail force model, given by Ref. [5] (NB: a negative sign is added where necessary due to difference in the sign of displacement. also see Eq. (9))

$$
\tilde{P}(f)=\frac{\tilde{z}(f)}{-\alpha_{\mathrm{W}}(f)+\alpha_{\mathrm{R}}(f)+\alpha_{\mathrm{C}}}
$$


where $\tilde{z}(f)$ is roughness amplitude at frequency $f, \alpha_{\mathrm{W}}(f), \alpha_{\mathrm{R}}(f)$ and $\alpha_{\mathrm{C}}$ are the receptances of the wheel, rail and contact spring. As indicated in Section III.B, $a_{w}(f) \approx a_{R}(f)$ at the frequency of Peak A. Thus, at this frequency the denominator in Eq. (33) reaches a local minimum, and as a result, the wheel/rail force exhibits a peak. On the other hand, as can be seen in Fig. 9, at about $180 \mathrm{~Hz}$ the receptance of the rail has a peak and is dominant over the wheel and contact spring. It is found in Ref. [30] that this peak depends on load speed: it will be shifted slightly to a lower frequency and its height will be reduced if the load speed is higher. Thus, according to Eq. (33), a dip appears to the wheel/rail force at this frequency and this dip appears at a slightly lower frequency for $350 \mathrm{~km} / \mathrm{h}$ than for 250 $\mathrm{km} / \mathrm{h}$.

Between $180 \mathrm{~Hz}$ and about $600 \mathrm{~Hz}$, the wheel/rail force increases with increasing frequency. This is mainly caused by rail receptance which reduces with frequency in this range, as shown in Fig. 9. For frequencies between about $1000 \mathrm{~Hz}$ and $2000 \mathrm{~Hz}$, the wheel/rail force is mainly controlled by the contact spring, resulting in a rather smoothly decreasing wheel/rail force, since the roughness decreases with increasing frequency. The wheel/rail force fluctuates strongly with frequency above about $2000 \mathrm{~Hz}$. The dips mainly correspond to the peaks in the wheel receptance.

The fact that, away from characteristic frequencies of the wheel/track system, the wheel/rail force increases with the train speed is mainly due to the fact that as train speed increases, the wavelength, and therefore the amplitude of the roughness, increases, bringing stronger excitation to the wheel/track system at a given frequency.

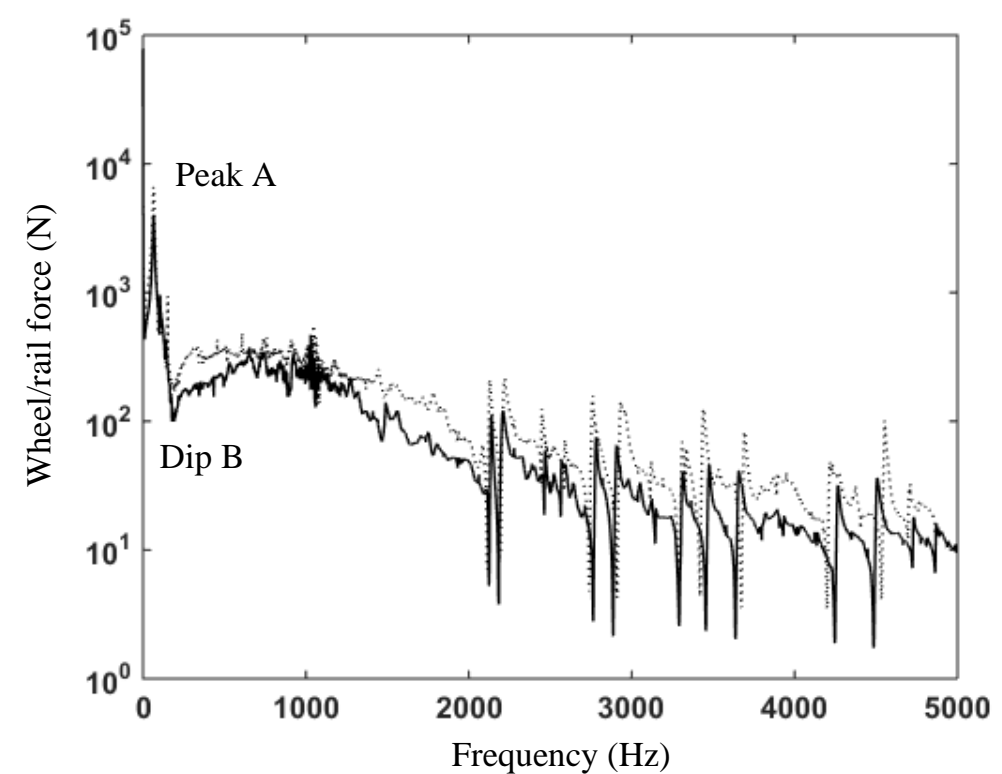

Fig. 11. Wheel/rail force due to a single wheelset moving at $250 \mathrm{~km} / \mathrm{h}(-)$ and $350 \mathrm{~km} / \mathrm{h}(\cdots \cdots)$. Peak A occurs at around $66 \mathrm{~Hz}$ and Dip B appears at about $180 \mathrm{~Hz}$.

\section{Due to four wheelsets belonging to two adjacent bogies}


Previous studies have shown that multiple wheelsets can interact with each other through the rail 592 [38], altering the wheel/rail force spectrum from what it is for a single wheelset. This interaction becomes strong if the vibration decay rate of the track is low, or the train speed is high. The track decay rates on ballastless tracks are typically lower than on ballasted tracks, with a minimum value around $0.5 \mathrm{~dB} / \mathrm{m}$. Consequently, the decay of vibration between wheelsets over the length of a vehicle (typically $18 \mathrm{~m}$ between bogies) is of the order of $10 \mathrm{~dB}$ so the interaction between these wheelsets can be neglected. Here a train speed of $250 \mathrm{~km} / \mathrm{h}$ is chosen to demonstrate the significance of the interaction even at lower speeds. Wheel/rail forces are produced for four wheelsets belonging to two adjacent bogies, since these four wheelsets are much closer to each other than other wheelsets. At $t=$ 0 , the 4th, 3rd, 2nd and 1st wheelsets are located at $-4.75 \mathrm{~m},-2.25 \mathrm{~m}, 2.25 \mathrm{~m}, 4.75 \mathrm{~m}$, respectively. The average of the four wheel/rail force magnitudes is compared in Fig. 12 with that when only a single wheelset is present. The ratio of them is shown in Fig. 13. It can be seen that, the difference in wheel/rail force between a single wheelset and four wheelsets is negligible for frequencies below about $180 \mathrm{~Hz}$, the rail-on-railpad resonance frequency. This may be explained by the high track decay rate in this frequency region. However, for higher frequencies, wheel/rail forces due to multiple wheelsets fluctuate more strongly with frequency, especially between $180 \mathrm{~Hz}$ and $2000 \mathrm{~Hz}$ where the track plays a more important role in determining the wheel/rail force. The variation can be as high as a factor of 8 . For frequencies higher than $2000 \mathrm{~Hz}$, the wheel/rail force is mainly affected by the wheel and therefore interactions between multiple wheels become weaker. In summary it may be reasoned that, for rolling noise prediction on a slab track, at least four wheelsets belonging to two adjacent bogies should be taken into account in wheel/rail force calculation.

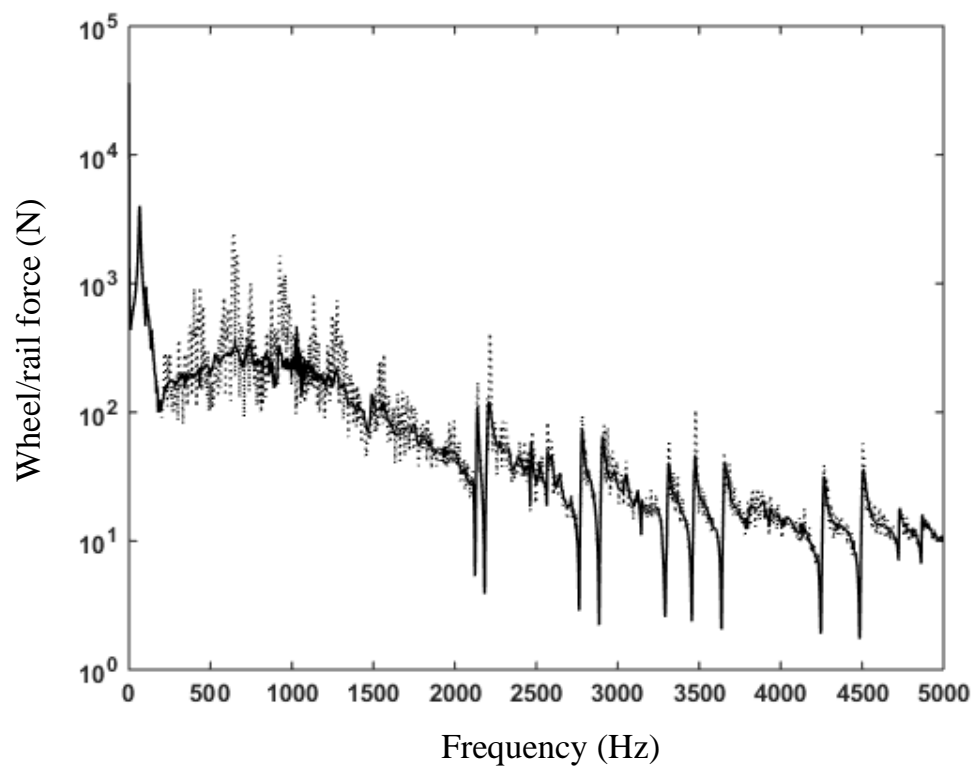

Fig.12. The average (….) of the four wheel/rail force magnitudes and that (in solid line) due to a single wheelset. Train speed $250 \mathrm{~km} / \mathrm{h}$. 


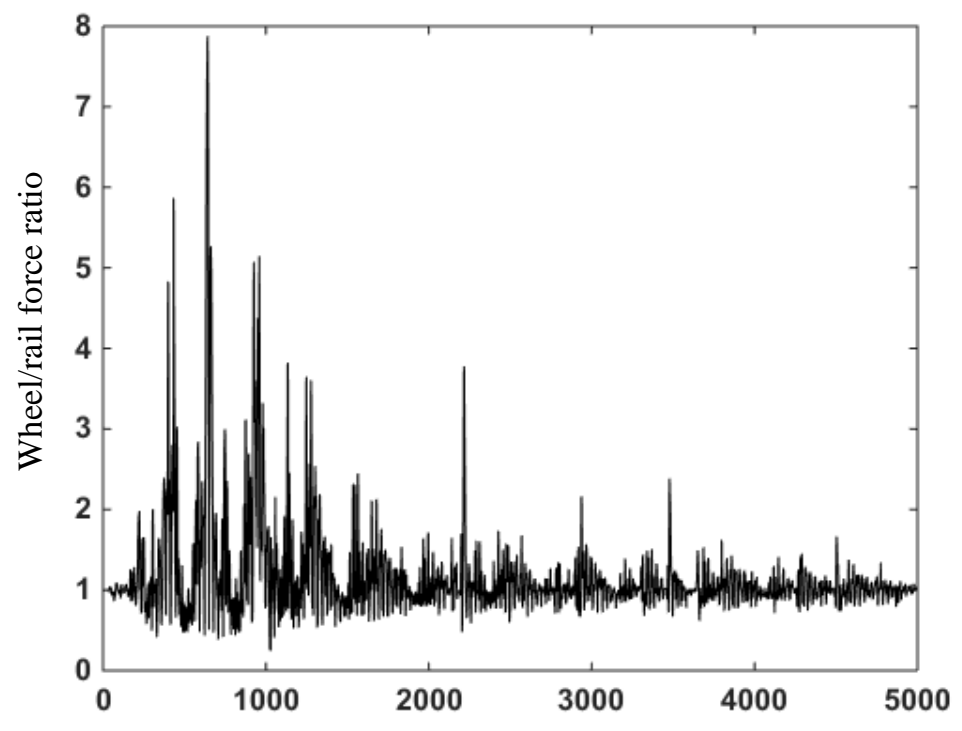

Fig.13. The ratio of the average of the four wheel/rail force magnitudes to the magnitude due to a single wheelset. Train speed $250 \mathrm{~km} / \mathrm{h}$.

\section{E. Rolling noise}

The prediction of rolling noise is described in this section. First, in Section E.1, a comparison is made between predicted rolling noise and measured pass-by noise. This comparison may serve as a preliminary validation of the prediction. Additional results are then presented in Sections E.2 and E.3.

\section{A comparison between prediction and measurement}

In this section, the modelling approach described in this paper is applied to predict the rolling noise for a train/track system for which measured rail roughness and pass-by noise data are available. Track and wheelset parameters are listed in Section III.A and the roughness spectrum is shown in Fig. 7.

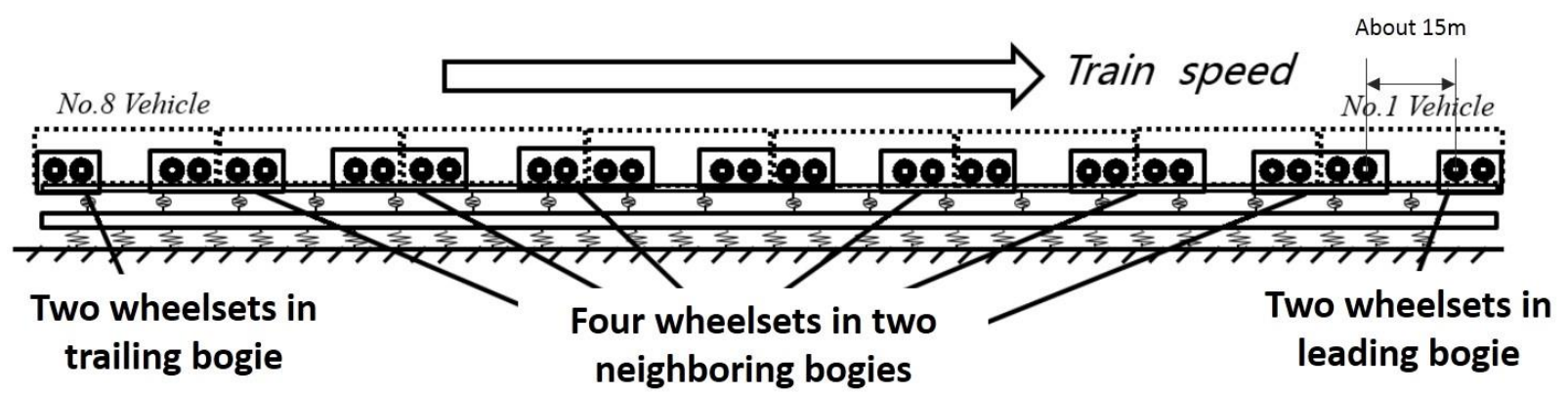

Fig. 14. The train with 8 vehicles, 16 bogies and 32 wheelsets.

As depicted in Fig. 14, the train is made up of eight vehicles, having 32 wheelsets interacting with each other through the track. However, in the wheel/rail force calculation it is difficult to include all the 32 wheelsets, and a simplification has to be made. Since the first two wheelsets are distant from 
the others, the wheel/rail forces at these two wheelsets are calculated by just considering interactions between them and the track, as if the other wheelsets were absent. The predicted wheel/rail forces are applied to the last two wheelsets by appropriate phase shifts. Then wheel/rail forces are calculated for the set of four wheelsets from the third to the sixth, with the others removed. The predicted wheel/rail forces are applied to other wheelsets by appropriate phase shifts.

The rolling noise is predicted and compared with measured pass-by noise for a specific receiver location, which is $25 \mathrm{~m}$ away from the track centre line and $1.2 \mathrm{~m}$ above the top of the rail. Note that the noise level is expressed as an equivalent level over the train passing time (the train length is 209 $\mathrm{m})$. Sound pressure spectrum levels in the 1/3-octave bands are shown in Fig. 15(a) for $160 \mathrm{~km} / \mathrm{h}$ and in Fig. 15(b) for $300 \mathrm{~km} / \mathrm{h}$. It can be seen that the prediction is relatively satisfactory for frequencies at which rolling noise is mainly determined by the rail (see Section E.3), between about $200 \mathrm{~Hz}$ and $2000 \mathrm{~Hz}$ for $160 \mathrm{~km} / \mathrm{h}$ (however, it is noticed in Fig. 15(a) that rolling noise is under predicted around $1000 \mathrm{~Hz}$ for some unknown reasons) and between $315 \mathrm{~Hz}$ and $2000 \mathrm{~Hz}$ for $300 \mathrm{~km} / \mathrm{h}$. At lower frequencies the predicted level is much lower than the measured one. This may be attributed to various reasons, for example, the presence of other noise sources such as auxiliary equipment and aerodynamic noise (measured sound pressure levels are found to have dependences on train speed $(V$ in $\mathrm{km} / \mathrm{h}$ ) of $52 \log _{10}(V)$ for $125 \mathrm{~Hz}, 50 \log _{10}(V)$ for $250 \mathrm{~Hz}$ and $45 \log _{10}(V)$ for $315 \mathrm{~Hz}$. They indicate that aerodynamic noise is important at these low frequencies); uncertainty in the roughness at long wavelengths; that the rail radiation from the vertical motion is quite strongly directed upwards, meaning the microphone position is in regions of low sound pressure, while in practice reflections from the car-body will redirect this sound out towards the microphone. In addition, according to Ref. [12], the part of the rail with a gap below it will dominate the radiation above about $400 \mathrm{~Hz}$ but at low frequencies it becomes very small, like a quadrupole, whereas the region where the rail is attached to the slab (i.e. over the fasteners) has a monopole dependence and will dominate instead. Therefore the current model may under-predict the rail noise below about $400 \mathrm{~Hz}$.

It is also observed that, above $2000 \mathrm{~Hz}$, the predicted level is higher than the measured one. This may be caused by inaccuracies in the modelling of wheel sound radiation. 

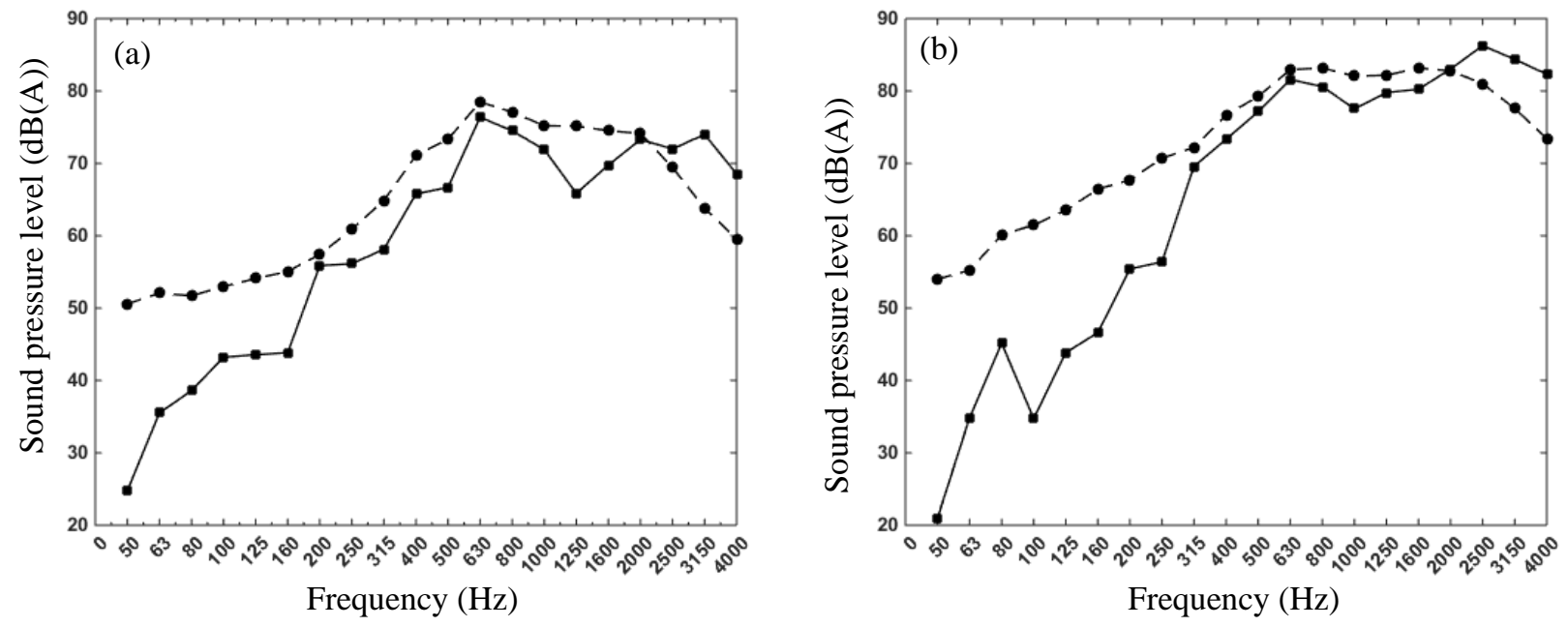

Fig. 15. A-weighted 1/3-octave band sound pressure level for two train speeds, (a) $160 \mathrm{~km} / \mathrm{h}$ (a) and (b) $300 \mathrm{~km} / \mathrm{h}$. $\longrightarrow$, prediction; - - , measurement.

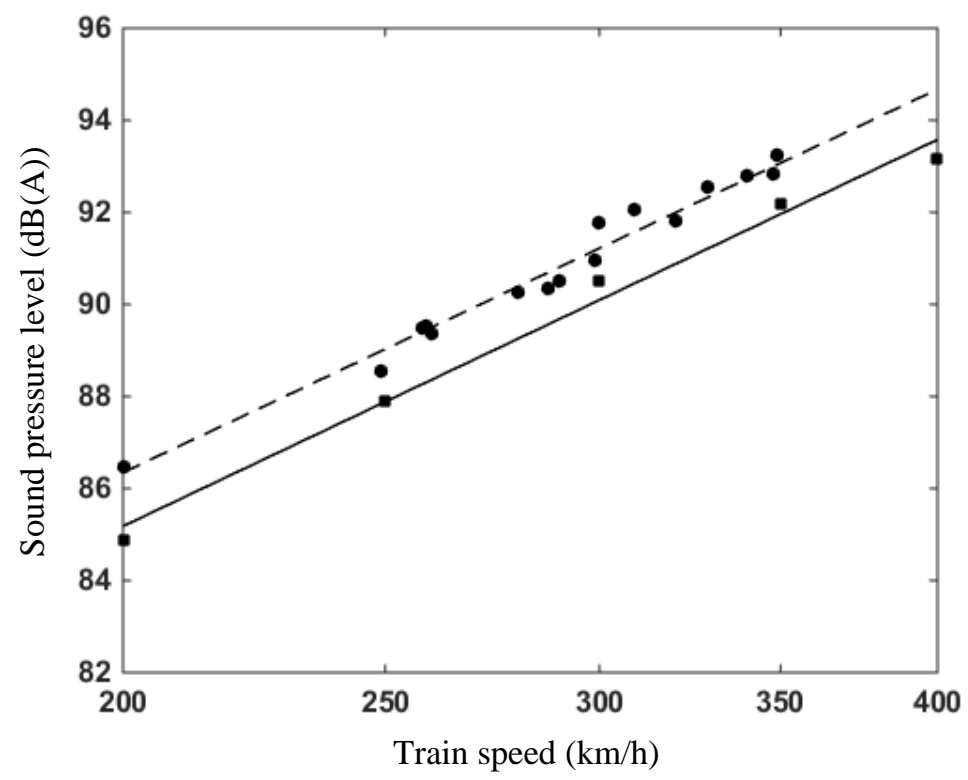

Fig. 16. A-weighted sound pressure level as function of train speed. ——, prediction; - - - measurement.

\section{Rolling noise dependence on train speeds}

In this and the next section, sound pressure levels radiated from the rail, slab and four wheels belonging to two neighbouring bogies are predicted for two locations in the field. The first location is $7.5 \mathrm{~m}$ away from the track central line and $3.5 \mathrm{~m}$ above the top of the rail, while the second one is $25 \mathrm{~m}$ away at the same height as the first one. The overall sound pressure level is calculated to be an 


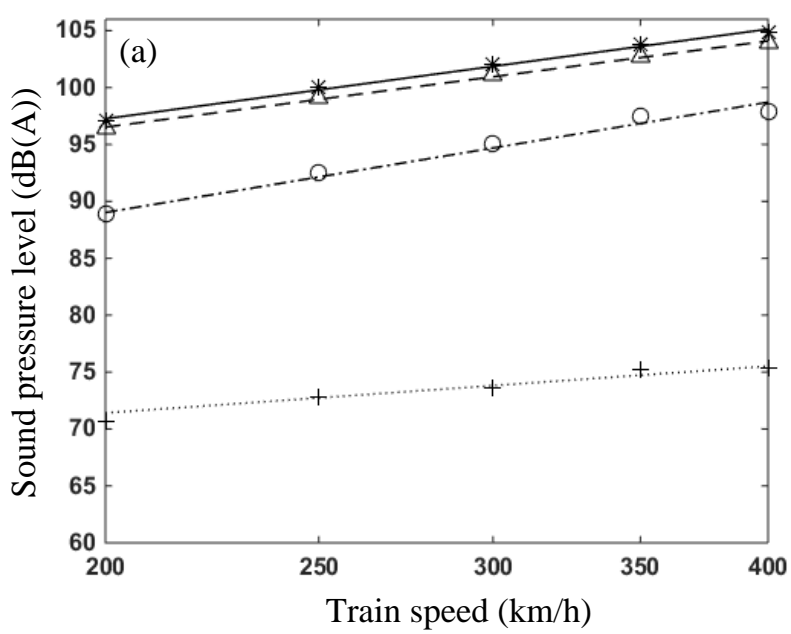
speed. equivalent level based on the passing time of the four wheelsets, which is $9.5 \mathrm{~m}$ divided by the train

Overall A-weighted sound pressure levels are predicted for five train speeds: $200 \mathrm{~km} / \mathrm{h}, 250 \mathrm{~km} / \mathrm{h}$, $300 \mathrm{~km} / \mathrm{h}, 350 \mathrm{~km} / \mathrm{h}$ and $400 \mathrm{~km} / \mathrm{h}$. They are shown in Fig. 17(a) for the $7.5 \mathrm{~m}$ observation point and Fig. 17(b) for the $25 \mathrm{~m}$ one. From these results it can be seen that the contribution from the slab to the total level is negligible. For the first observation point, the contribution from the rail is dominant while for the second point, the noise level from the four wheels is higher than that from the rail.

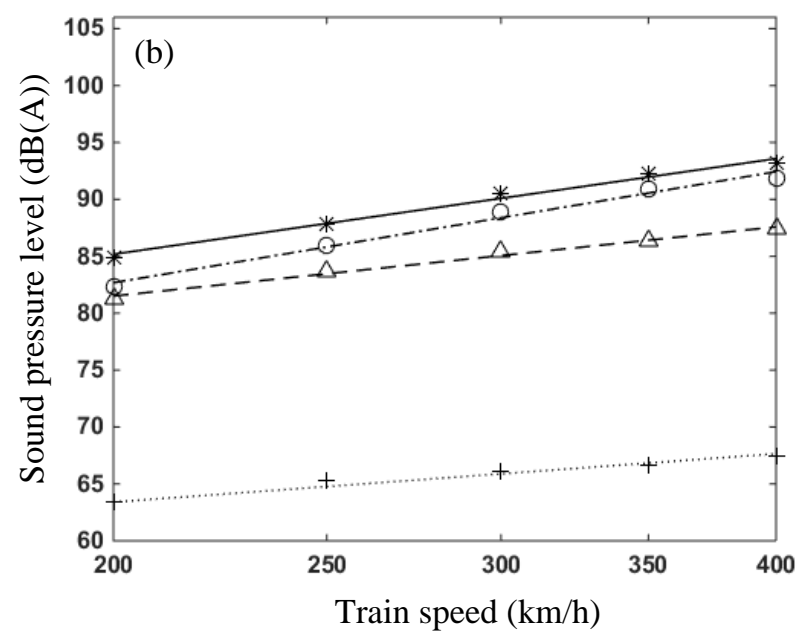

Fig. 17. A-weighted overall sound pressure levels at (a) the first location (distance $7.5 \mathrm{~m}$, height $3.5 \mathrm{~m}$ ) and (b) the second location (distance $25 \mathrm{~m}$, height $3.5 \mathrm{~m}$ ). *, total; o, due to wheel; $\Delta$, due to rail; +, due to slab.

Again, the predicted overall levels show a train speed dependence of $a \log _{10}(V)$. Values of the coefficient $a$ are listed in Table 2. It can be seen that the coefficient depends on the receiver location, especially for the rail. The contribution from the wheels has the highest rate of increase with the train speed, with $a$ being around 32 .

TABLE 2 Values of $a$ for Fig. 17

\begin{tabular}{|l|c|c|c|c|}
\hline & Total & Due to wheelsets & Due to rail & Due to slab \\
\hline $\begin{array}{l}\text { For the first point (distance } \\
7.5 \mathrm{~m}, \text { height } 3.5 \mathrm{~m})\end{array}$ & 26.2 & 32.2 & 25.1 & 13.6 \\
\hline $\begin{array}{l}\text { For the second point (distance } \\
25 \mathrm{~m}, \text { height } 3.5 \mathrm{~m} \text { ) }\end{array}$ & 27.9 & 32.4 & 20.2 & 14.1 \\
\hline
\end{tabular}

\section{Noise spectra due to wheel, rail and slab}

The A-weighted 1/3-octave band sound pressure spectra of the noise generated by the wheels, rail and slab separately are shown in Fig. 18 for the two observation points. For the first observation point, at $7.5 \mathrm{~m}$, the rail radiates the highest noise levels between $315 \mathrm{~Hz}$ and $2000 \mathrm{~Hz}$, while the noise levels from the wheelsets are the highest for higher frequencies. For frequencies below $200 \mathrm{~Hz}$, both the 


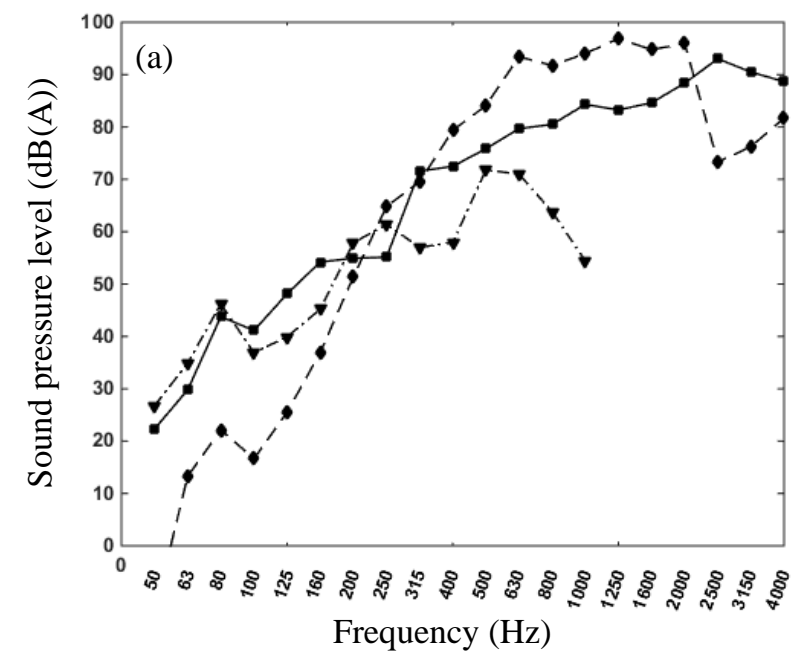
slab is only significant below $250 \mathrm{~Hz}$. wheels radiate much higher noise than the rail for frequencies between $50 \mathrm{~Hz}$ and $500 \mathrm{~Hz}$ and above $2000 \mathrm{~Hz}$. The rail and wheel produce similar noise levels between $500 \mathrm{~Hz}$ and $2000 \mathrm{~Hz}$. Again, the

Fig. 18. A-weighted 1/3-octave band sound pressure spectrum at (a) the first point (distance $7.5 \mathrm{~m}$, height $3.5 \mathrm{~m}$ ); (b) the second point (distance $25 \mathrm{~m}$, height $3.5 \mathrm{~m}$ ). __ $350 \mathrm{~km} / \mathrm{h}$.

\section{CONCLUSIONS}

An approach is described in this paper for modelling rolling noise for a high-speed train running on a slab railway track. Factors related to high-speed railways, such as wheel rotation, sound reflections from the slab, interactions between multiple wheelsets via the track, fast motion of the sources etc. are considered in a sufficiently detailed manner. However, there are still aspects of the model that can be improved, especially in determining the sound radiation from a moving and vibrating wheelset. The model also needs more thorough validation with dedicated field tests.

A preliminary investigation is presented of the characteristics of rolling noise for a typical highspeed train and track, including frequency spectra, dependence on train speed, contributions of the wheel, rail and slab etc. It can be concluded that:

(1) For high speeds, consideration of wheelset rotation is necessary. This is because rotation changes resonances/anti-resonances of a wheelset, resulting in differences in wheel/rail force. Wheel rotation may shift an important peak in the sound power spectrum of a wheelset from one 1/3-octave band to another, changing the 1/3-octave band result.

(2) Interactions between multiple wheelsets via the track should be considered. This is because modern high-speed tracks normally use relatively soft railpads and the vibration decay rate of the rail is low from a low frequency ( $180 \mathrm{~Hz}$ for the track considered in this paper). 
(3) Rolling noise (sound pressure level in $\mathrm{dB}(\mathrm{A})$ ) shows a dependence on train speed ( $V \mathrm{in} \mathrm{km} / \mathrm{h}$ ) of the form of $a \log _{10}(V)$, where, $a$ is approximately 27 , consistent with previous studies.

705 706 707 708

(4) Regarding the relative importance of wheel, rail and slab, it is demonstrated that slab vibration is important only for frequencies lower than about $250 \mathrm{~Hz}$ (for the railpads considered); rolling noise is mainly contributed by the rail and wheel (but the slab plays an important role by reflecting sounds emitted from the wheel and rail) and for frequencies higher than about $2000 \mathrm{~Hz}$, the wheel is the main contributor. In terms of the A-weighted overall sound pressure level, the relative importance of wheel and rail depends on the location of observation.

(5) For the situation studied, the noise from the wheel increases more quickly with train speed than that from the rail.

\section{CONFLICT OF INTEREST STATEMENT}

We, the authors of this paper, certify that we have no affiliation with, or involvement in, any organisation or entity with any financial interest, or nonfinancial interest in the subject matter or materials discussed in this manuscript.

\section{ACKNOWLEDGEMENT}

This work is funded by the National Key R\&D Program of China (2016YFE0205200), and the National Natural Science Foundation of China (U1834201).

\section{REFERENCES}

[1] X. Sheng, M. Li, Z. Zhu, Using microphone array data to analyze source contributions of a high-speed train to pass-by noise, Proceedings of the 7th All-Russian Research to Practice Conference with International Participation 'Protection against Increased Noise and Vibration', 19 - 21 March, 2019.

[2] H. M. Noh, S. Choi, S. Hong, S. W. Kim, Investigation of noise sources in high-speed trains, Proceedings of the Institution of Mechanical Engineers, Part F: Journal of Rail and Rapid Transit 228(3) (2014) 307-322.

[3] B. Mauclaire, Noise generated by high speed trains. New information acquired by SNCF in the field of acoustics owing to the high speed test programme, Proceedings of Inter-Noise (1990) $371-374$.

[4] D. J. Thompson, E. Latorre Iglesias, X. W. Liu, J. Zhu, Z. Hu, Recent developments in the prediction and control of aerodynamic noise from high-speed trains, International Journal of Rail Transportation 3 (3) (2015) 119-150. 
[5] D. J. Thompson, Railway noise and vibration: Mechanisms, Modelling and Means of Control, Elsevier, 2009.

[6] P. J. Remington, Wheel/rail rolling noise, I: Theoretical analysis, Journal of the Acoustical Society of America 81 (1987) 1805-1823.

[7] D. J. Thompson, B. Hemsworth, N. Vincent, Experimental validation of the TWINS prediction program, Part I: description of the model and method, Journal of Sound and Vibration 193 (1996) 123-135.

[8] C. J. C. Jones, D. J. Thompson, Extended validation of a theoretical model for railway rolling noise using novel wheel and track designs, Journal of Sound and Vibration 267 (2003) 509-522.

[9] L. Castel, P. E. Gautier, N. Vincent, J. P. Goudard, $350 \mathrm{kph}$ running tests to assess a new railway noise model, Proceedings of Inter-Noise (1993) 1467-1470.

[10] D. J. Thompson, C. J. C. Jones, A review of the modelling of wheel/rail noise generation, Journal of Sound and Vibration 231 (2000) 519-536.

[11] X. Zhang, G. Squicciarini, D. J. Thompson, Sound radiation of a railway rail in close proximity to the ground, Journal of Sound and Vibration 362 (2016) 111-124.

[12] X. Zhang, D. J. Thompson, G. Squicciarini, Sound radiation from railway sleepers, Journal of Sound and Vibration 369 (2016) 178-194.

[13] X. Zhang, D.J. Thompson, E. Quaranta, G. Squicciarini, An engineering model for the prediction of the sound radiation from a railway track, Journal of Sound and Vibration 461 (2019) 114921.

[14] T. X. Wu, D. J. Thompson, On the parametric excitation of the wheel/track system, Journal of Sound and Vibration 278 (2004) 725-747.

[15] T. X. Wu, D. J. Thompson, On the rolling noise generation due to wheel/track parametric excitation, Journal of Sound and Vibration 293 (2006) 566-574.

[16] Anders Nordborg, Hyo-In Koh, Comparison of two different models describing railway noise generation and radiation, Proceedings of Inter-Noise (2016) 7527-7536.

[17] A. Nordborg, Wheel/rail noise generation due to nonlinear effects and parametric excitation, Journal of the Acoustical Society of America 111(4) (2002)1772-1781.

[18] Yang, D. J. Thompson, Time-domain prediction of impact noise from wheel flats based on measured profiles, Journal of Sound and Vibration 333 (2014) 3981-3995.

[19] A. Guiral, Development of a Vehicle-Track Interaction Model for Mid- and HighFrequency Problems. Application to Wheel-Rail Noise, PhD Thesis, TECNUN -University 
of Navarra, 2014.

[20] J. Han, S. Q. Zhong, X. Zhou, X. B. Xiao, G. T. Zhao, X. S. Jin, Time-domain model for wheel-rail noise analysis at high operation speed, Journal of Zhejiang University-Science A 18(8) (2017) 593-602.

[21] D. J. Thompson, Wheel-rail noise generation, Part V: inclusion of wheel rotation, Journal of Sound and Vibration 161 (1993) 467-482.

[22] J. Fayos, L. Baeza, F. D. Denia, J. E. Tarancón, An Eulerian coordinate-based method for analysing the structural vibrations of a solid of revolution rotating about its main axis, Journal of Sound and Vibration 306 (2007) 618-635.

[23] B. Luis, J. Giner-Navarro, D. J. Thompson, J. Monterde, Eulerian models of the rotating flexible wheelset for high frequency railway dynamics, Journal of Sound and Vibration 449 (2019) 300-314.

[24] E. Ntotsios, D. J. Thompson, M. F. M. Hussein, The effect of track load correlation on ground-borne vibration from railways, Journal of Sound and Vibration 402 (2017) 142-163.

[25] X. Sheng, Y. Liu, X. Zhou, The response of a high-speed train wheel to a harmonic wheelrail force, Journal of Physics: Conference Series 744 (2016) 012145.

[26] X. Sheng, C. J. C. Jones, D. J. Thompson, Responses of infinite periodic structures to moving or stationary harmonic loads, Journal of Sound and Vibration 282 (2005) 125-149.

[27] X. Sheng, Generalization of the Fourier transform-based method for calculating the response of a periodic railway track subject to a moving harmonic load, Journal of Modern Transportation 23 (2015) 12-29.

[28] X. Sheng, T. Zhong, Y. Li, Vibration and sound radiation of slab high-speed railway tracks subject to a moving harmonic load, Journal of Sound and Vibration 395 (2017) 160-186.

[29] X. Sheng, M. Li, C. J. C. Jones, D. J. Thompson, Using the Fourier-series approach to study interactions between moving wheels and a periodically supported rail, Journal of Sound and Vibration 303 (2007) 873-894.

[30] T. Mazilu, M. Dumitriu, C. Tudorache, et al, Using the Green's functions method to study wheelset/ballasted track vertical interaction, Mathematical and Computer Modelling 54 (2011) 261-279.

[31] A. Pieringer, W. Kropp, J. C. O. Nielsen, The influence of contact modelling on simulated wheel/rail interaction due to wheel flats, Wear 314 (2014) 273-281.

[32] X. Sheng, X. Xiao, S. Zhang, The time domain moving Green function of a railway track and its application to wheel-rail interactions, Journal of Sound and Vibration 377 (2016) 
$133-154$.

[33] X. Sheng, Y. Peng, X. Xiao, Boundary integral equations for sound radiation from a harmonically vibrating body moving uniformly in a free space, The Journal of the Acoustical Society of America 146 (2019) 4493-4506.

804

[34] T. Zhong, G. Cheng, X. Sheng et al., Vibration and sound radiation of a rotating train wheel subject to a vertical harmonic wheel-rail force, Journal of Modern Transportation 26, 8195 (2018).

[35] D. A. Bies, C. H. Hansen, Engineering Noise Control, Theory and Practice, 4th Edition, Spon Press (2009).

[36] J. Ryue, S. Jang, D. J. Thompson, A wavenumber domain numerical analysis of rail noise including the surface impedance of the ground, Journal of Sound and Vibration 432 (2018) 173-191.

[37] T. Mazilu, Green's functions for analysis of dynamic response of wheel/rail to vertical excitation, Journal of Sound and Vibration 306 (2007) 31-58.

[38] T. X. Wu, D. J. Thompson, Vibration analysis of railway track with multiple wheels on the rail, Journal of Sound and Vibration 239 (2001) 69-97.

[39] ORE B 176 Bogies with steered or steering wheelsets. Report No. 1: specifications and preliminary studies. Vol. 2, Specification for a bogie with improved curving characteristics. 819 